This article has been scanned by iThenticat No plagiarism detected

Volume 3, Issue 5, October 2021

p. $266-280$

\title{
ANALYSIS OF HUMAN CAPITAL INDICATORS IN THE ENVIRONMENT OF THE IRAQI ECONOMY FOR THE PERIOD (2004-2017)
}

http: //dx.doi.org/10.47832/2757-5403.5-3.24

\section{Sohaila Abdul-Zahra AL-HUJAIMI ${ }^{1}$ \& Nidal Shaker Jawdat AL-HASHEMI²}

\begin{abstract}
:
The Process of rapid Economic growth provides the opportunity for countries the creation of human capital capable of increasing productivity, improving job opportunities and raising the quality level of community life, but the process of preparing it requires an efficient and effective educational and training system on the one hand, and providing the highest possible health level as a key to increasing production and raising productivity on the other hand. This research has dealt with the analysis of human capital indicators for the period (2004-2017) in Iraq. the study concluded that to these indicators of knowledge - education - health -training- income, are the main pillars for achieving economic growth in all areas of life during the study period. The study recommends giving attention to the human capital and employing it in production process in a way that reduces societal disparities and enhances, perhaps economic growth.
\end{abstract}

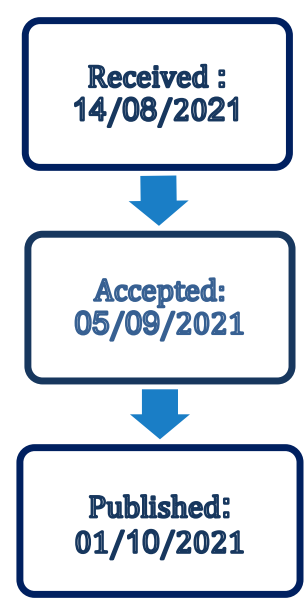

Key words: Human Capita, Knowledge, Education, Health, Economic Growth.

\footnotetext{
${ }^{1}$ Dr. , Al-Mustansiriya University, Iraq, Sohayla1973@yahoo.com, https://orcid.org/0000-0001-7615-3028

2 Prof. Dr. , Al-Mustansiriya University, Iraq, dr.nidhaljawdat@gmail.com, https://orcid.org/0000-0003-1596$\underline{8797}$
}

Copyright $($ C Published by IJHER Journal, www.ijherjournal.com Rimar Academy, Fatih, Istanbul, 34093 Turkey

All rights reserved 


\title{
تحليل مؤشرات رأس المال البشري في بيئة الاقتصاد العراقي للمدة (2017-2004)
}

\author{
سضيلة عبد الزهرة الحجيمي 3
}

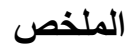

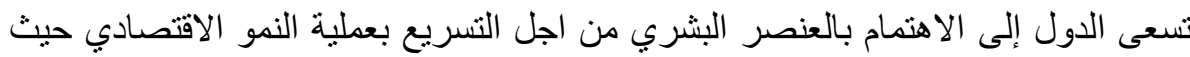

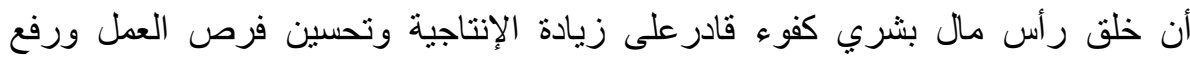

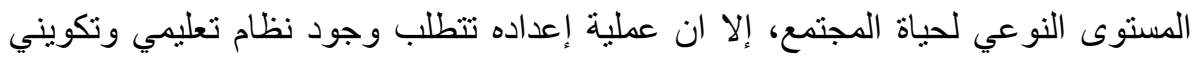

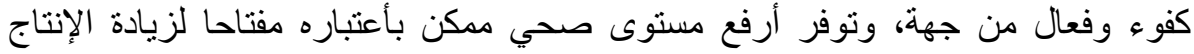

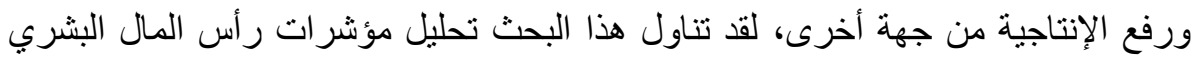

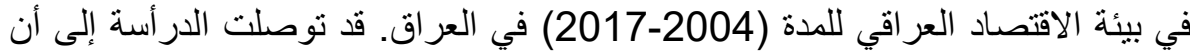

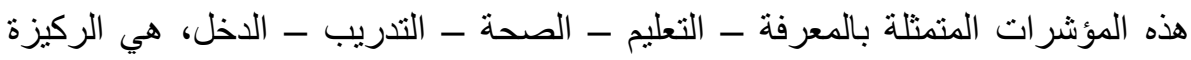

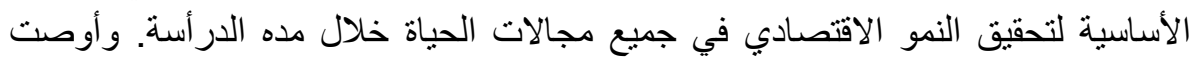
الدرأسة بضرورة الاهتمام بر أس المال البشري وتوظيفه في العملية الإنتاجية على نحو يقلل

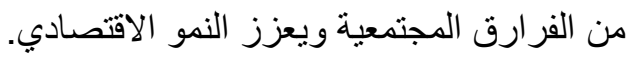
الكلمات الافتتاحية: رأس المال البشري، المعر الافرفة، التعليم، الصحة، النمو الاقتصادي.

يؤكد الاقتصاديون بمختلف مذاهبهم وتوجهاتهم الفكرية على اهمية العنصر البشري ودوره الفاعل في عملية الإنتاج وبرز

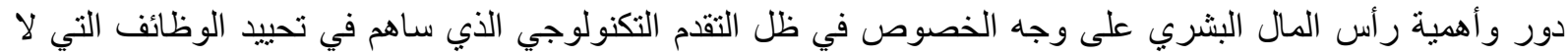
تحتاج إلى مهارات عالية وعمل على خلق وظائف جديدة نركز على المعرفة وتعمل على التأثير في الأهمية النسبية

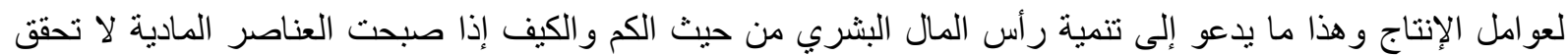

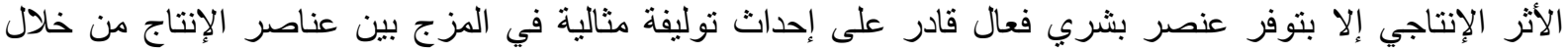

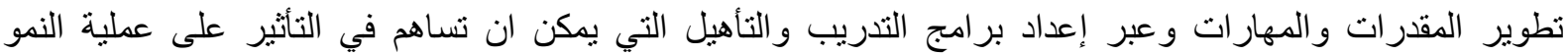

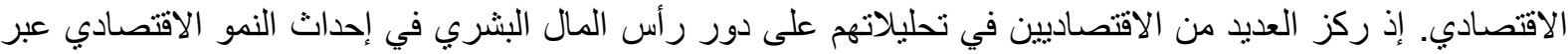
إدر اجه في دالة الإنتاج باعتباره عامل إنتاجي تر اكمي.

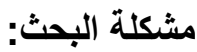

بالنظر لما يواجهه الاقتصاد العراقي من التحديات نتيجة الدمار والتخريب الذي سببه ويسببه عدم الاستقرار الأمني

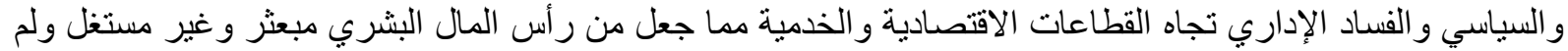

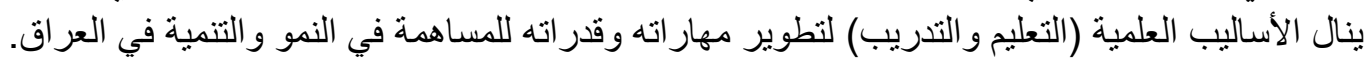

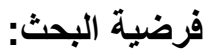

إن انخفاض تر اكمات رأس المال البشري سيكون سبب رئيسيا في ضعف تكوين الملاكات الكفو عة التي تثكل عائقا امام تحقيق النمو الاقتصادي في البلد.

هدف البحث:

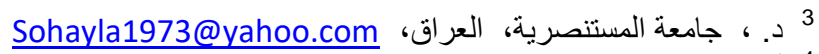
4 أ. د. ، جامعة المستتصرية، العراق، 
تحليل مؤشرات رأس المال البشري على معدل النمو الاقتصادي في العراق من خلال استخدام بعض المؤشرات.

تم اتخاذ المنهج تحليلي في أسلوب البحث، وقد تم تقسيم البحث إلى ثلاثة مطالب اولها مفهوم رأس المال البشري و النمو البه الاقتصادي والمطلب الثاني العلاقة بين رأس المال البشري والنمو الاقتصادي، بينما تضمن المطلب الثالث بنحليل مؤشرات رأس المال البشري و النمو الاقتصادي في بيئة الاقتصاد العر اقي للمدة 2004-2017.

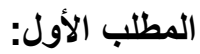

مفهوم رأس المال البشري والنمو الاقتصادي (إطار مفاهيمي) أولا: مفهوم رأس المال البشري

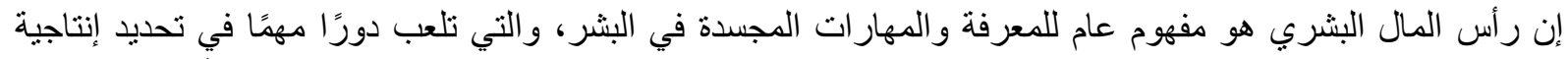

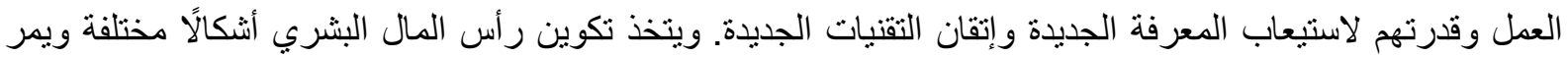

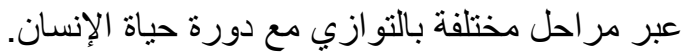

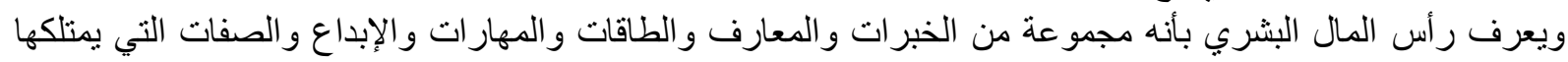

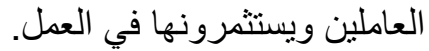

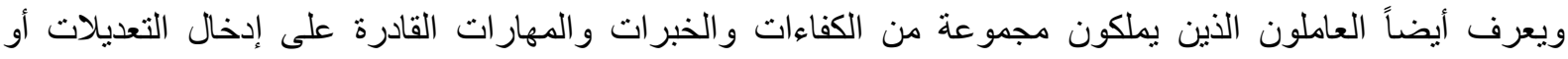

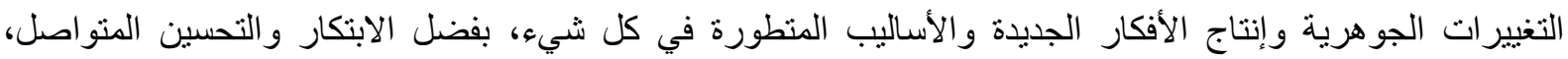
و العقول المفكرة التي تكون ملمة بمعرفة كبيرة تجعل المنظمة قادرة على التميز عالمياً من خلال الاستجابة لرغبات الإنات

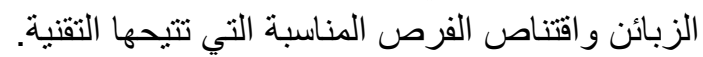

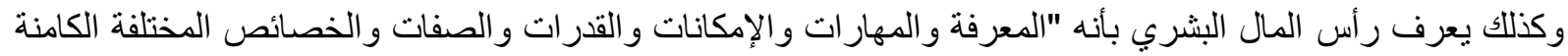

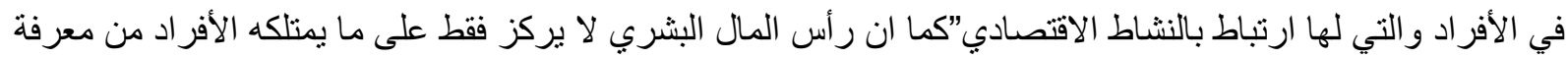

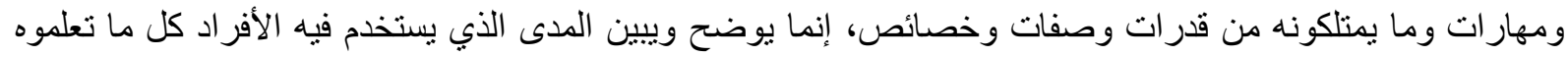

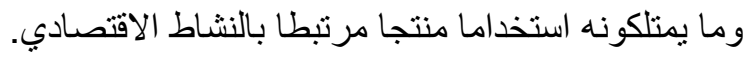

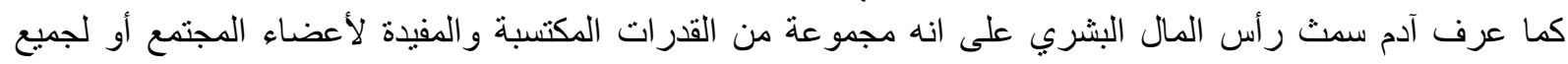

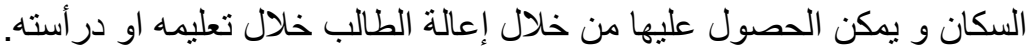

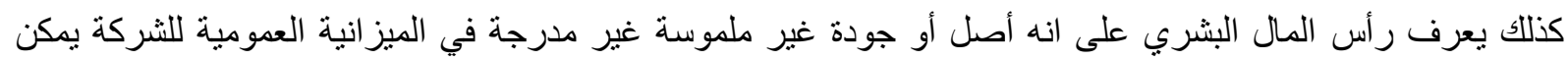

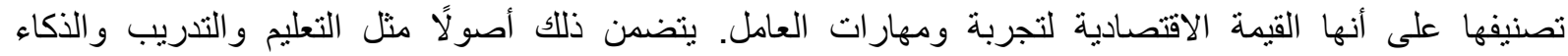

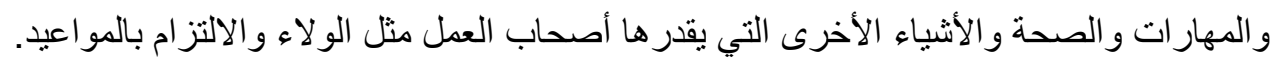

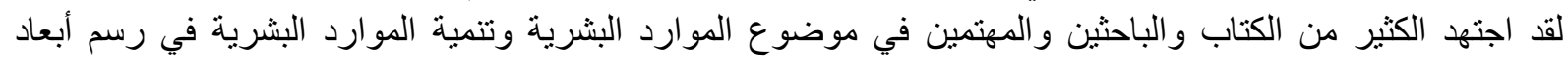

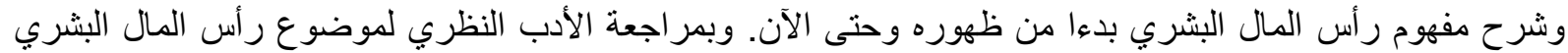

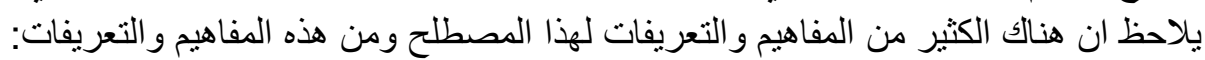

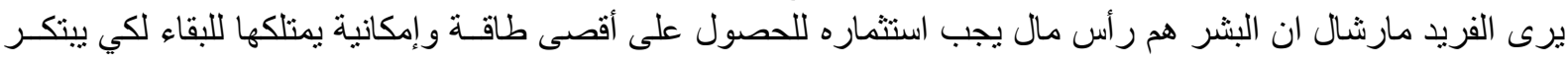

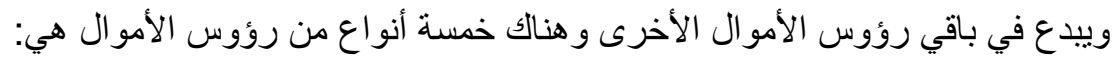

1. رأس المال المادي: ويقصد به ر أس المال المالي و النقدي. 2.

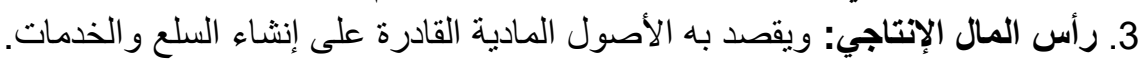

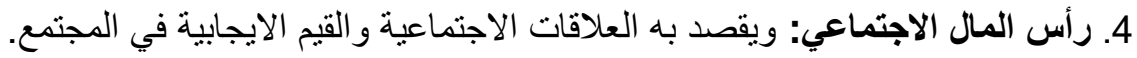
5. رأس المال البشري: ويقصد باهي القدر بات الإنتاجية الموروثنة أو المكتسبة.

ويعرف برنامج الأمم المتحدة الإنمائي رأس المال البشري "هو الزيادة في إنتاجية العمال و الموظفين لامتلاكهم المهارات

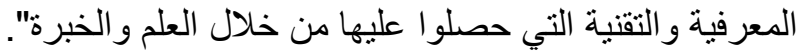


كما أن تقرير التنمية العربية الإنسانية لعام 2010، يعرف رأس المال البشري على انه التوجهات و المعارف و القدرات

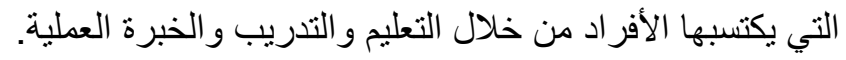

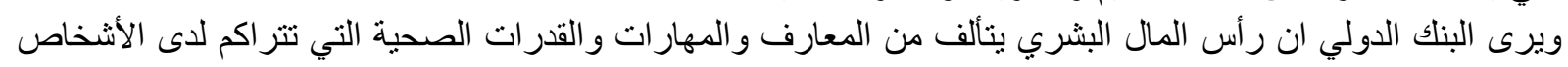

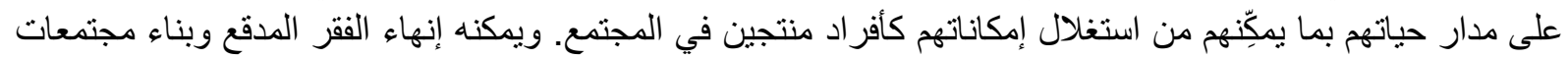

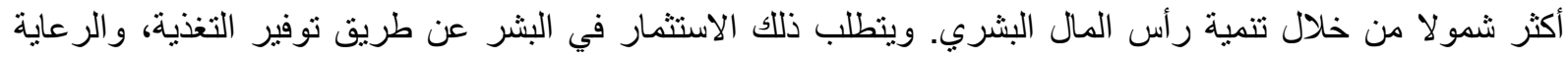

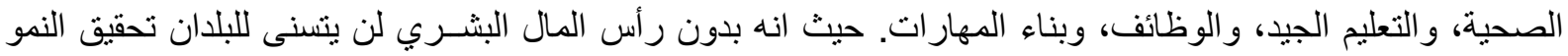

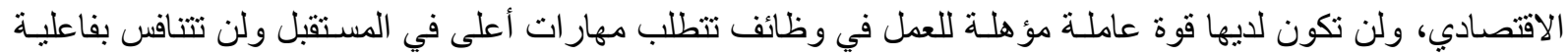

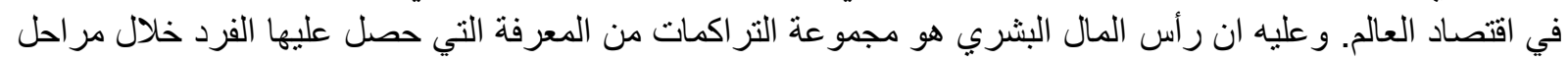

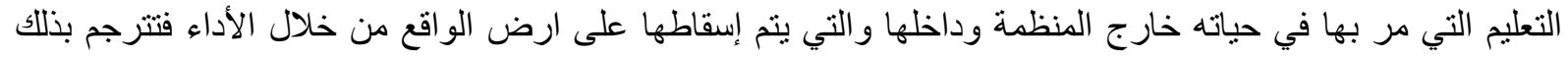

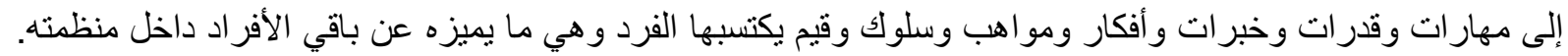

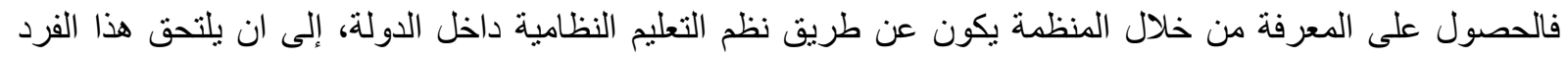

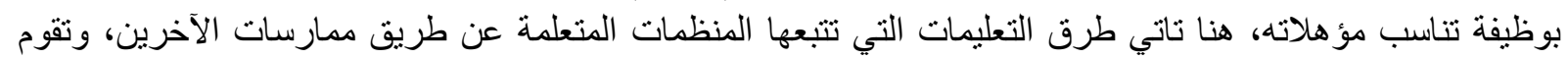

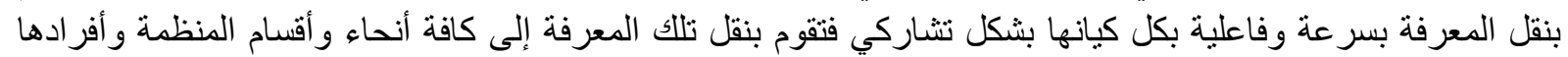

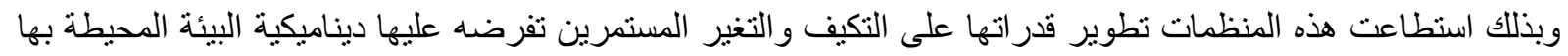

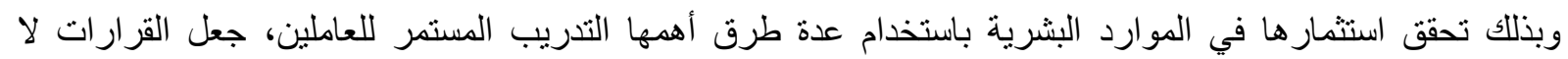

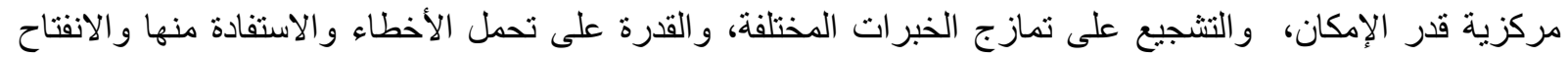

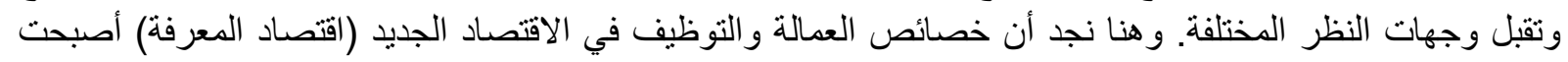

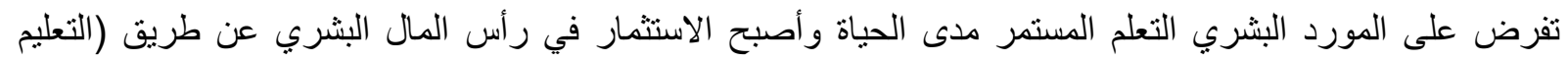

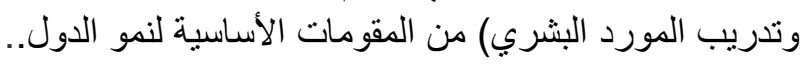

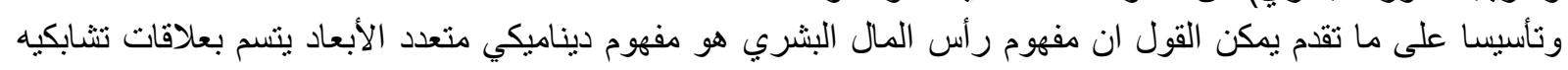

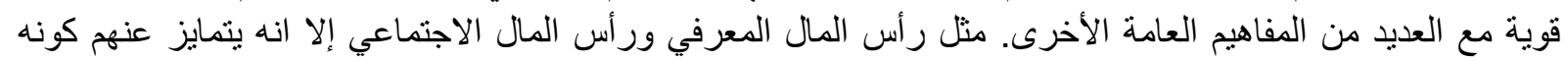

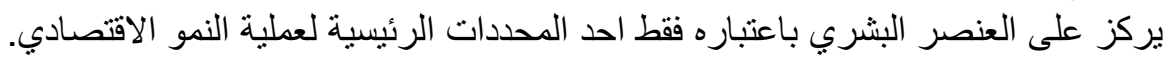

ثانيا: مفهوم النمو الاقتصادي (المفهوم، العناصر) 1- - 20 - مفهوم النمو الاقتصادي.

برزت العديد من التعاريف لمصطلح النمو الاقتصادي منها:

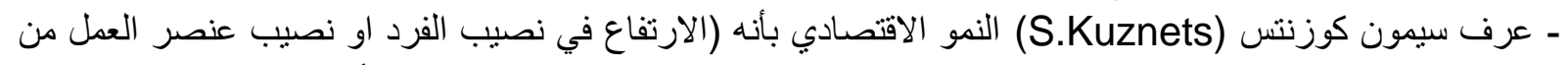

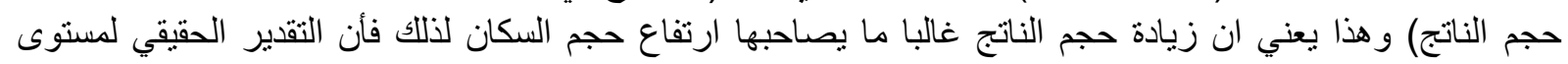

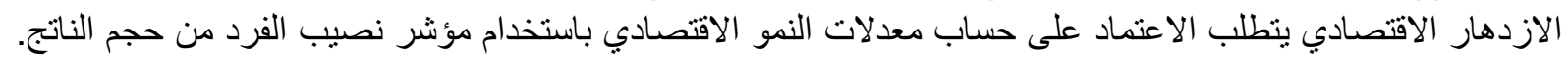

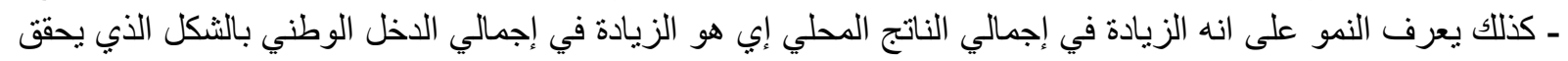

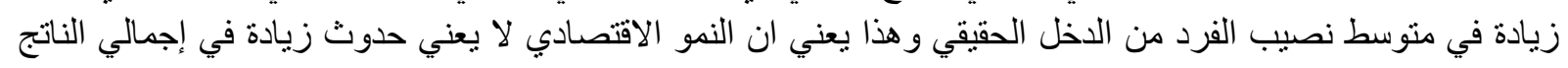

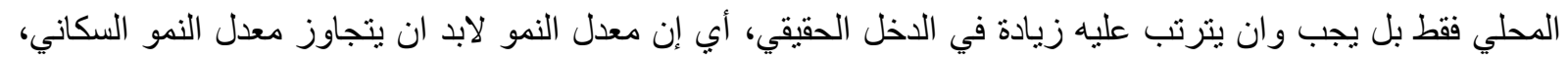

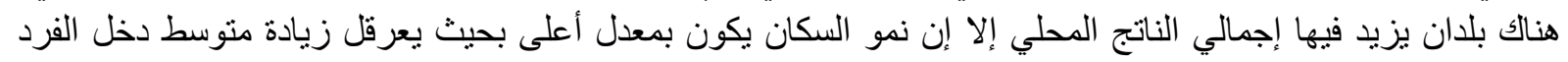

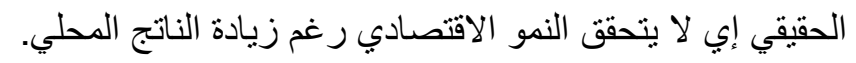

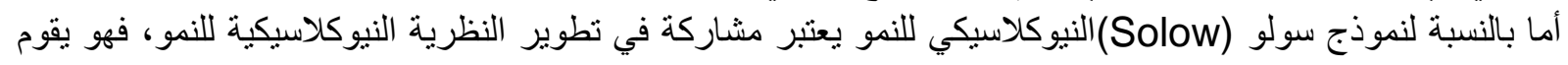

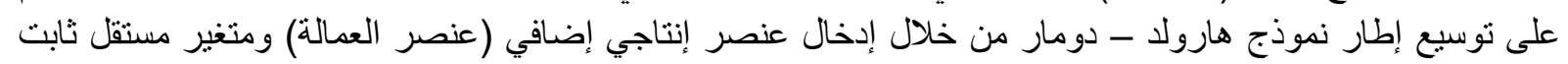

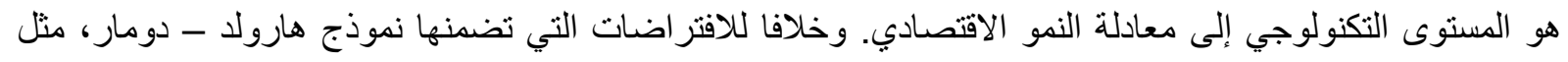

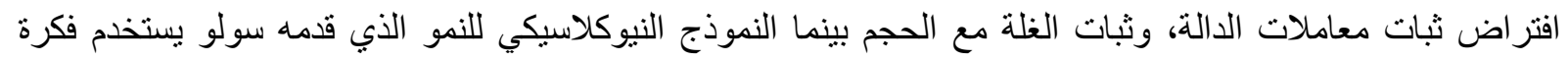

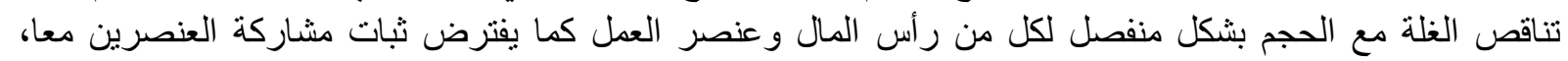

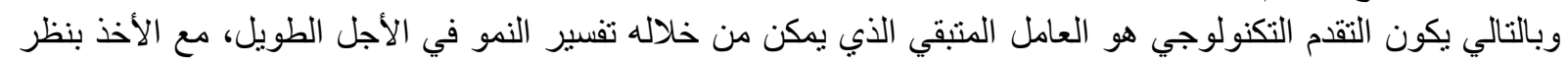

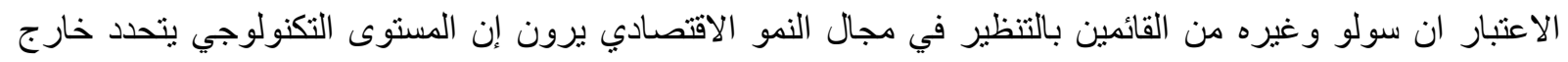

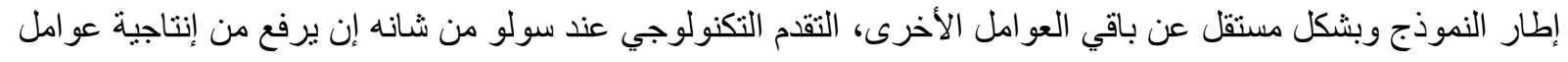


الإنتاج الكلية، إذن النمو الاقتصادي هو الدحرك الأساسي الذي يساعد على تحسين مستوى معيشة الأفراد ويوفرلهم الزيادة في السلع والخدمات وفرص عمل جديدة فرص اكثر للقضاء على الفقر وتحقيق الرفاهية. من التعريفات السابقة للنمو الاقتصادي يمكنتا ان نستخلص أن: ـ النمو الاقتصادي لا يعني فقط حدوث زيادة في إجمالي الناتج المحلي بل لابد وان يترتب عليه زيادة في دخل الفرد

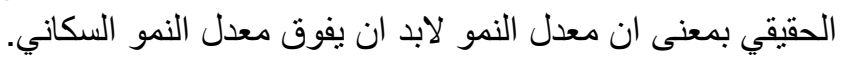

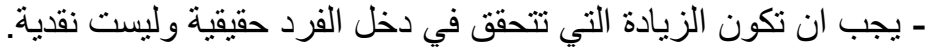

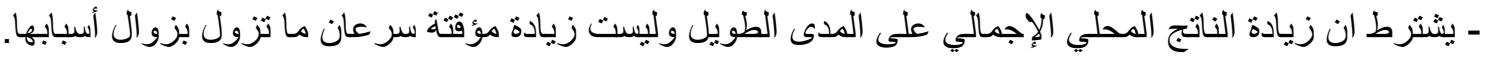
2- 2 عناصر النمو الاقتصادي إن معرفة كيفية حصول عملية النمو الاقتصادي، هو معرفة مصادر النمو الاقتصادي، وهو هدف نظريات النمو

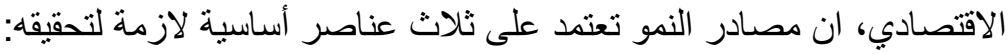
1. العمل: ان العامل المؤثر بشكل كبير في عملية الإنتاج هو العمل، ويقصد به القدرات الفكرية والفية والجسمية التي يسنطيع الإنسان استخدامها في العملية الإنتاجية، وينعلق حجم اليد العاملة بعدد السكان القادرين على العمل و النشطين الجاهزين له له وبساعات العمل التي يبذلها كل عامل. الإنهان.

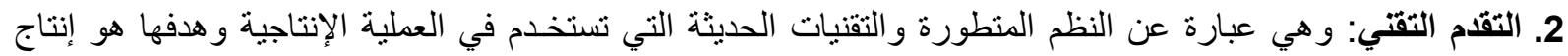

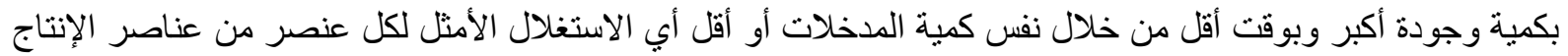
ويتولد التطور التكنولوجي والتقني عن طريق الاكتشافات العلمية الجديدة والابتكارات والبحث العلمي والاختر اعات الحديثة. 3. رأس المال: مجموع السلع التي توجد في وقت معين في اقتصاد معين، ويساعد على نوسيع الإنتاج بواسطة

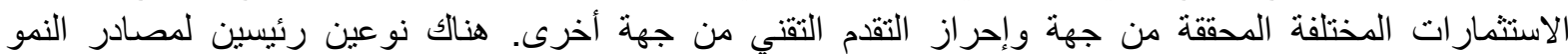

- مصادر النمو المباشرة: وهي المرتبطة بتر اكم مدخلات العملية الإنتاجية

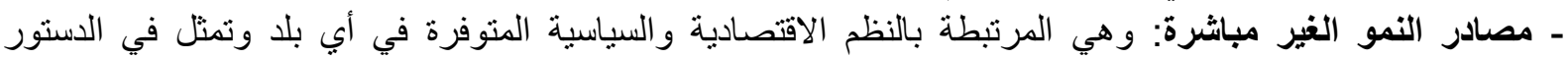

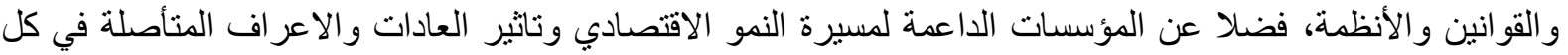

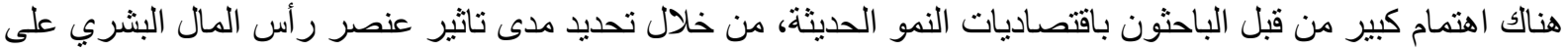

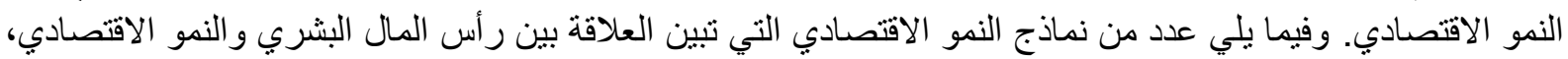

:

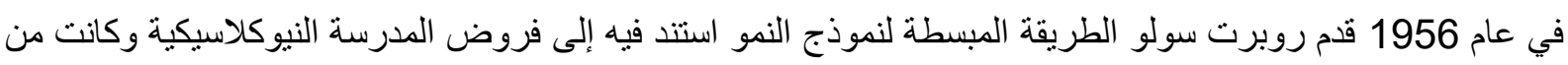

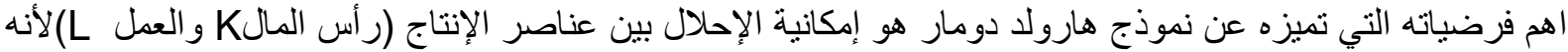

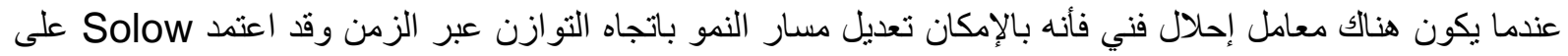
دالة الإنتاج (كوب دوكلاص) من اجل تحديد إطار تحليلي لأسباب النمو وحركته عبر الزمان الزمان وفي العام العام 1957 قدم

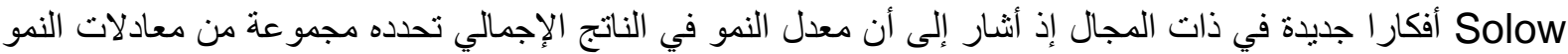

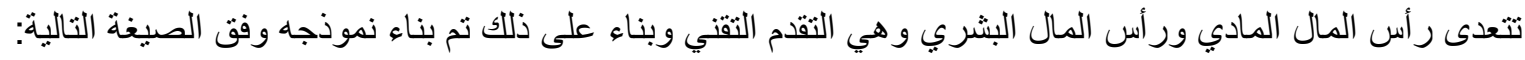
$Y t=A t * f(k t \cdot L t)$ 
إذ أن AfL هو مشتقة الدالة الأصلية إلى العمل ويمثل الإنتاجية الحدية للعمل MPL وان Afk تمثل الإنتاجية الحدية لر أس المال MPK باعتبار ان حصة رأس المال a وحصة العمل B من الناتج ويمثلان المرونة الجزئية لكل من العمل

$$
\text { B }
$$

و على افتر اض ان حصة عائد رأس المال مكملة لحصة عائد العمل عند ثبات غلة عائد الحجم ابي ان دالة الإنتاج مقيدة

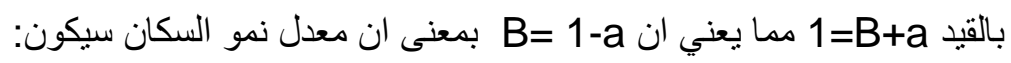
$\mathrm{y}^{\wedge *} / \mathrm{y}=\mathrm{A}^{\wedge *} / \mathrm{A}+\mathrm{a} \mathrm{K}^{\wedge *} / \mathrm{K}+(1-\mathrm{a}) \mathrm{L}^{\wedge *} / \mathrm{L}$

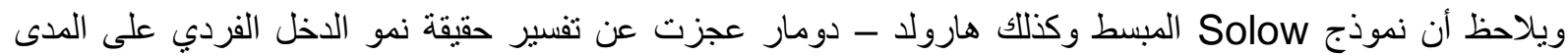

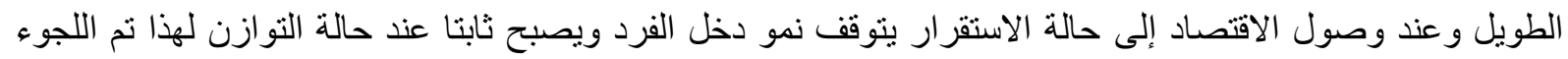
إلى إدخال مفهوم التقام التقني (A) الذي ينظر إلى انه مساهمة خارجية داعمة للناتج المحلي ويزيد من كفاءة عوامل الإنا الإنتاج و هناك عدة تأثير ات للتقدم التقني.

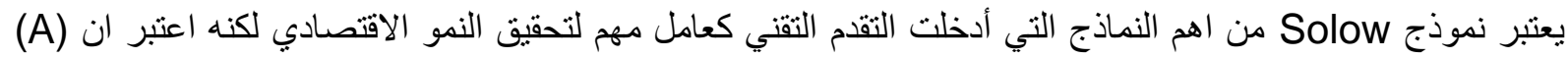

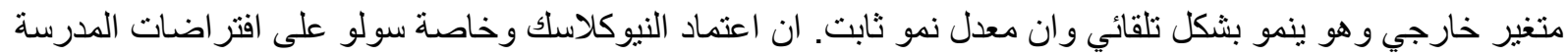

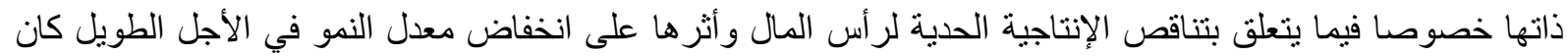

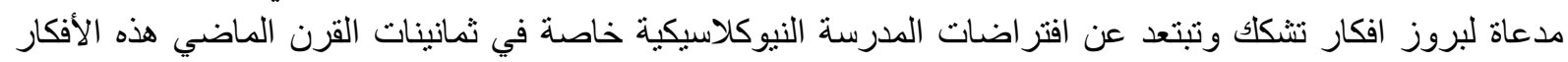

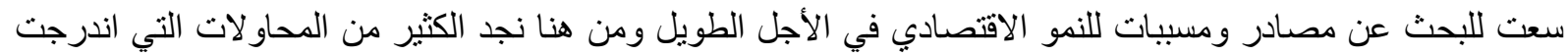

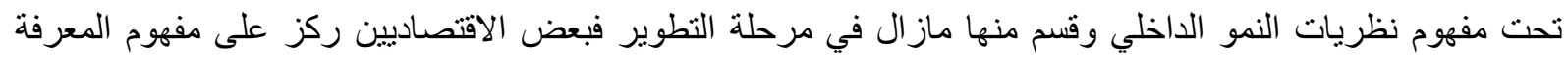
و البحث والتطوير مثل Poul Romer عام 1990 الذي انطلق من ان الأفكار والمعرفة تختلف عن العوامل الاقتصادية لانها غير قابلة للمنافسة.

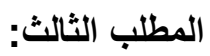

تحليل مؤشرات رأس المال البشري في بيئة الاقتصاد العراقي للمدة (2004-172017). 1- مؤشرات رأس المال البشري في العراق 2004-2017

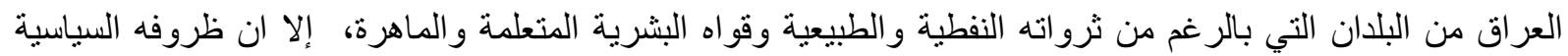

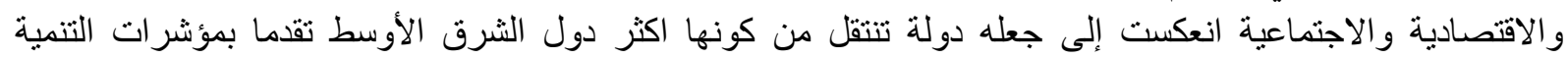

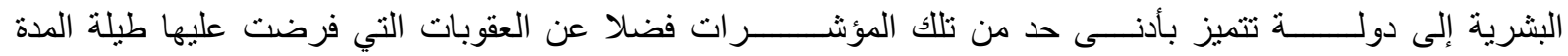

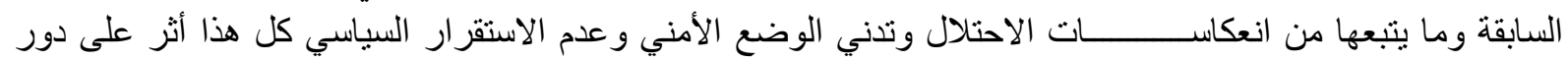

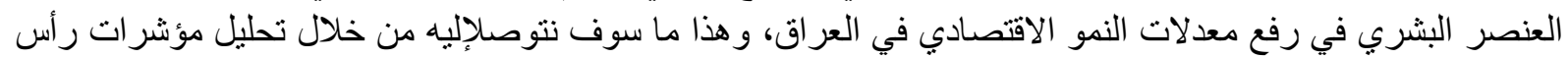

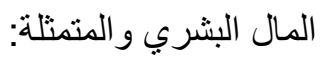

\section{أولا- مؤشرات رأس المال البشري في العراق للمدة 2004-2017}

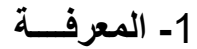

إن المبادئ التي اقرتها القمة العالمية حول مجتمع المعلومات التي أقيمت في جنيف 2003 نصت على الته تمكين الدول

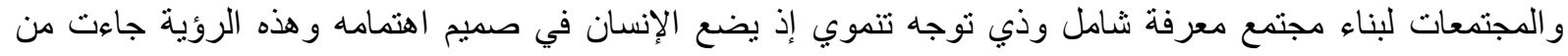

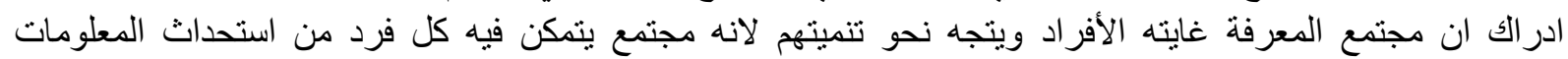

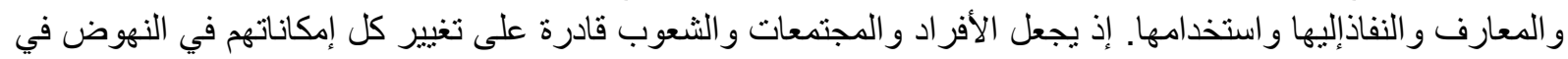
التنمبة وتطوير حياة الأفر اد.

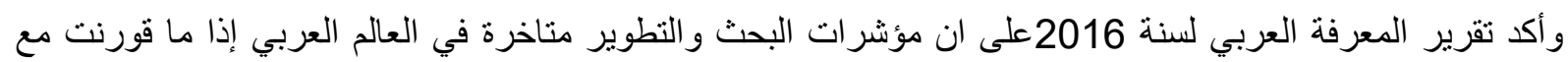

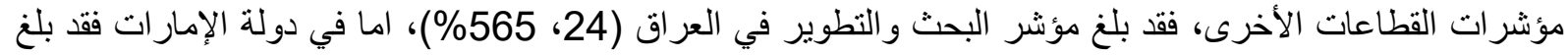

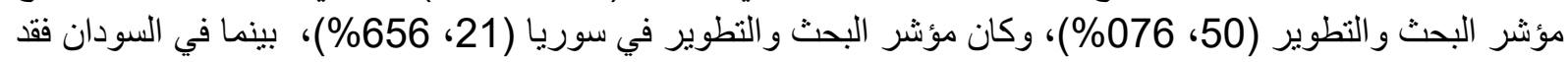

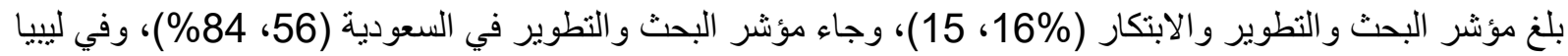

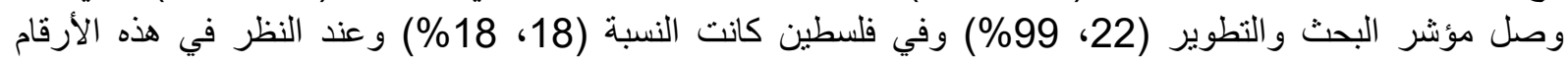
الإحصائية يتضح انها نأثرت بمجمو عة من العو امل (المؤسساتية والاجتماعية والاقتصادية و التنموية). 
2- 20 الواقع التعليمي في العراق للمدة 2004-2017.

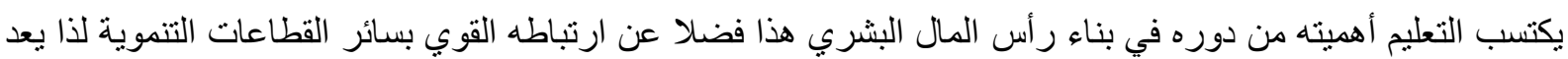

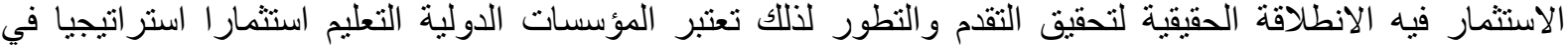

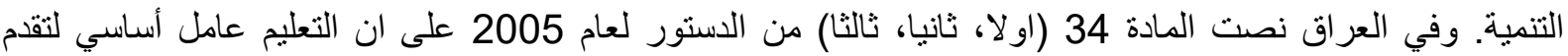

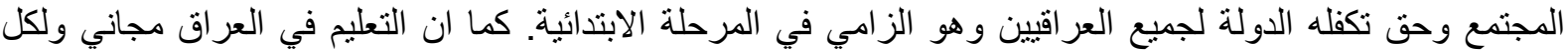

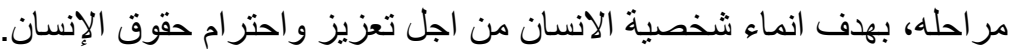

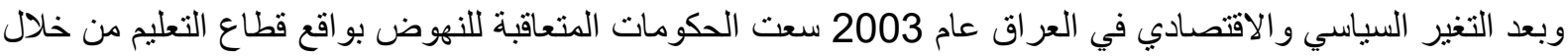
تذليل المعوقات التي تقف امام هذا القطاع الحيوي ووفقا للنطور الذي يشهذه العالم، ومن اهم المؤشرات التي تعكس لنا

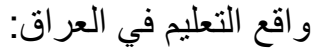

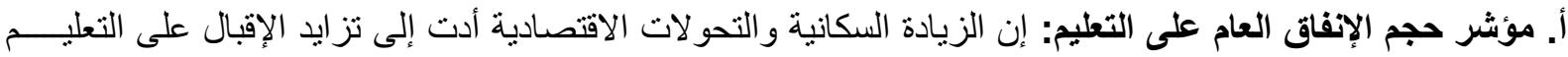

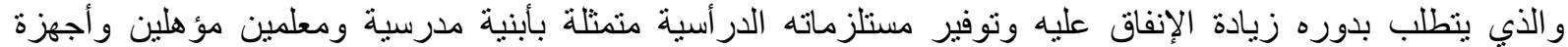

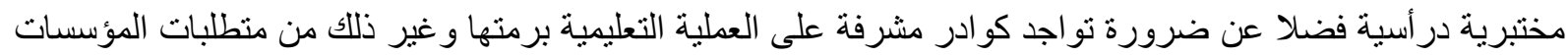

جدول (1) الإنفاق الحكومي على قطاع التعليم العام في العراق2004 -2017 (بالدو لار)

\begin{tabular}{|c|c|c|c|c|c|c|}
\hline 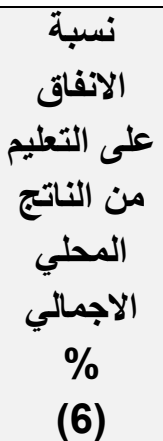 & 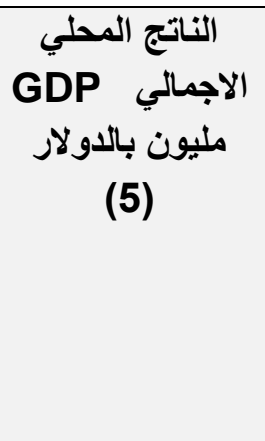 & 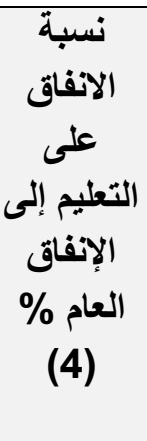 & $\begin{array}{c}\text { (بالدقات العام) } \\
\text { (3) }\end{array}$ & $\begin{array}{c}\text { معدل النمو } 1 \text { (2) } \\
\text { (2) }\end{array}$ & ملالإنفاتى على & السنة \\
\hline 3.23 & 53235358.7 & 5.35 & 22104.26 & & 1182.34 & 2004 \\
\hline 2.19 & 73533598.6 & 6.11 & 17954.51 & -7.15 & 1097.78 & 2005 \\
\hline 2.17 & 95587954.8 & 6.19 & 22827.46 & 28.79 & 1413.85 & 2006 \\
\hline 2.22 & 111455813.4 & 6.35 & 31100.58 & 39.58 & 1973.49 & 2007 \\
\hline 3.35 & 157026061.6 & 8.86 & 49793.27 & 123.52 & 4411.25 & 2008 \\
\hline 5.72 & 130643200.4 & 14.21 & 44929.08 & 44.74 & 6385.21 & 2009 \\
\hline 4.19 & 162064565.5 & 10.54 & 55001.70 & -9.18 & 5798.55 & 2010 \\
\hline 3.65 & 217327107.4 & 10.08 & 67314.24 & 17.07 & 6787.98 & 2011 \\
\hline 3.74 & 254225490.7 & 9.03 & 90171.16 & 19.99 & 8145.03 & 2012 \\
\hline 3.88 & 273587529.2 & 9.93 & 91657.83 & 11.77 & 9103.71 & 2013 \\
\hline 3.73 & 266332655.1 & 11.89 & 70333.52 & -8.12 & 8364.27 & 2014 \\
\hline 4.66 & 194680971.8 & 13.23 & 59157.58 & -6.44 & 7825.27 & 2015 \\
\hline 4.77 & 196924141.7 & 14.51 & 56359.19 & 4.51 & 8178.46 & 2016 \\
\hline 4.59 & 221665709.5 & 13.74 & 63866.42 & 7.30 & 8776.05 & 2017 \\
\hline$\% 2$ & $\% 10.5$ & $\% 6$ & $\% 7.7$ & $-\% 5$ & $\% 15$ & المركب نمو \\
\hline
\end{tabular}

المصدر: وزارة التخطيط، الجهاز المركزي للإحصاء، الحسابات القومية. 
ـ العمود (5، 1) الجهاز المركزي للإحصاء، الحسابات القومية، تم تحويل المبلغ بالدولار.

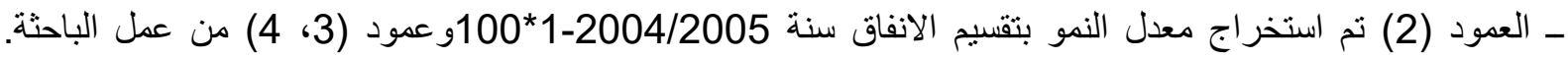

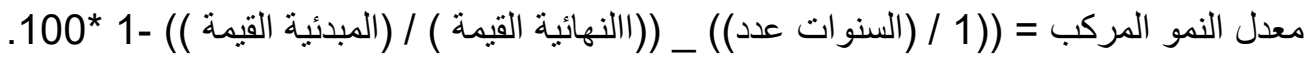

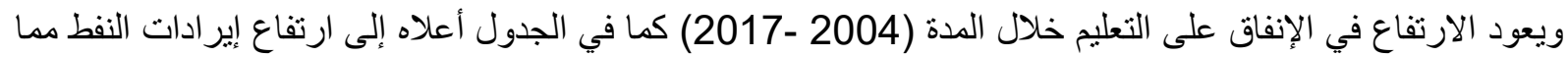

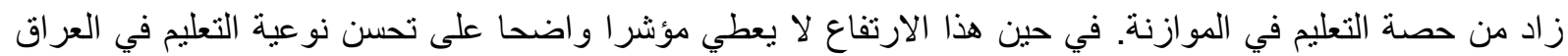

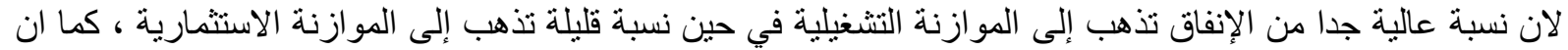

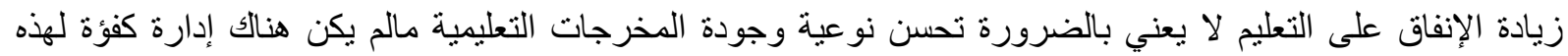

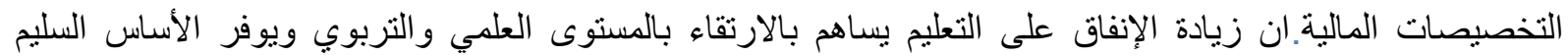

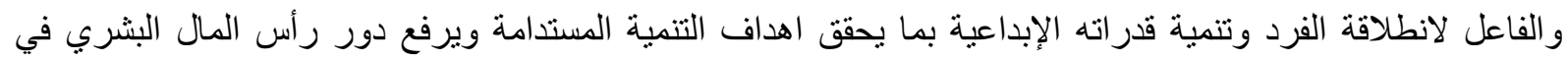
النمو الاقتصادي. 3- الواقع الصحي في العراق.

تعمل التتمية البشرية على الاهتمام بالمستوى الصحي و التعليمي للأطفال، وتوجد مر احل متعددة لتنمية صحة الإنسان منها

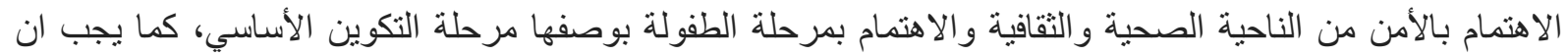

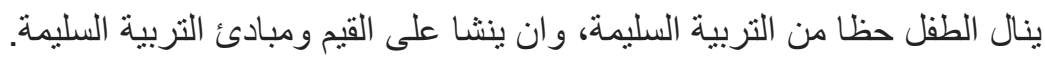

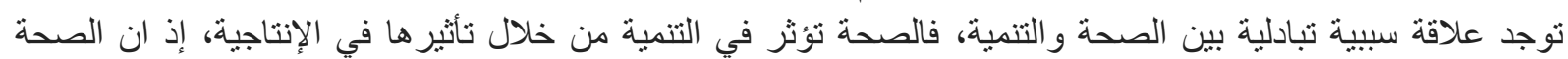

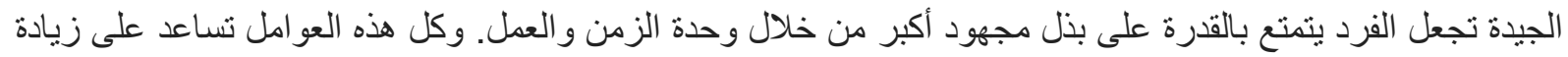

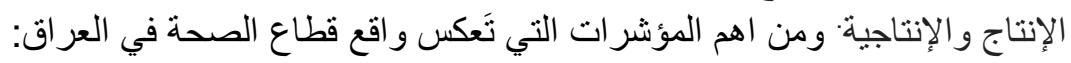

\section{أ ـ مؤشر الإنفاق العام على الصحة:}

هناك شحة في التمويل وتدني الأول وية الممنوحة للصحة في الموازنة الحكومية، ومن الطبيعي تكون الطريقة التي يتم

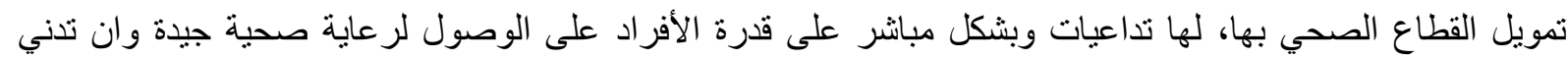

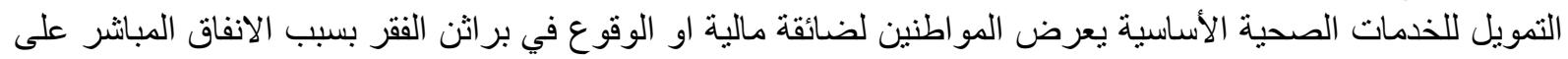

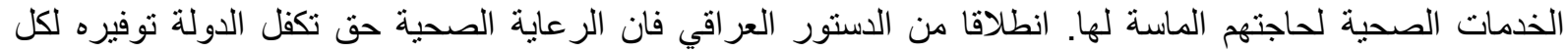

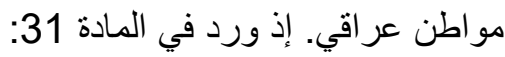

أولا: لكل عراقي الحق في الرعاية الصحية، ومن اولويات الدولة الاهتمام بالصحة العامة، وتكفل وسائل الوقاية و العلاج، بانشاء مختلف انواع المستثفيات و المؤسسات الصناء الصحية.

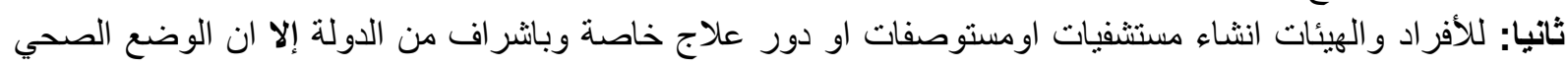

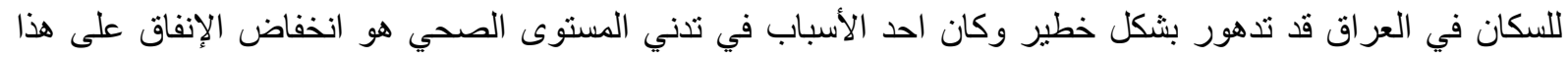

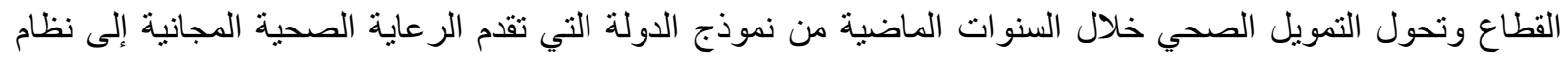

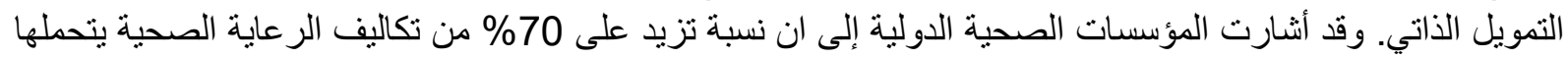

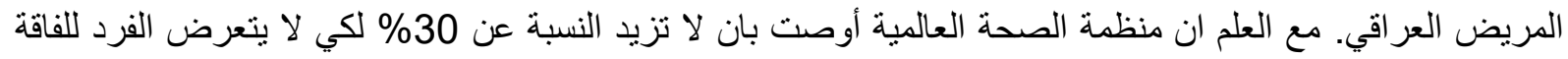

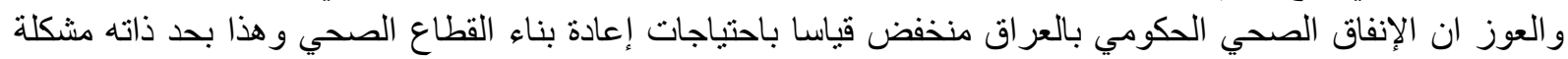

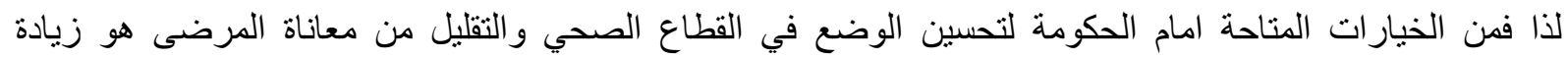

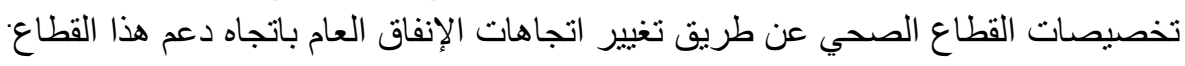

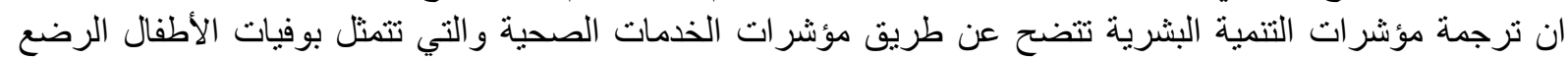

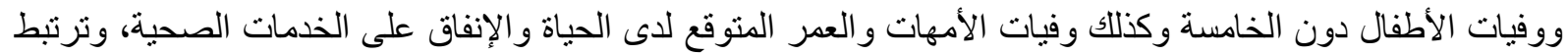

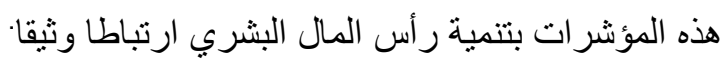

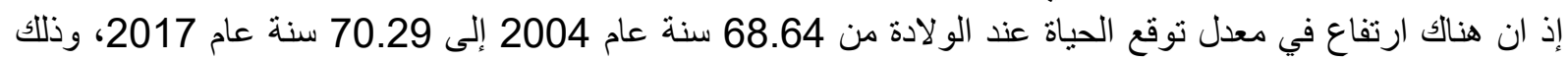

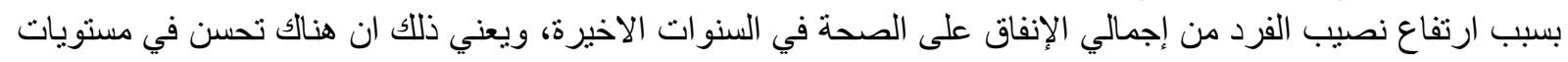

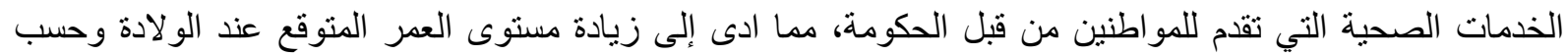
التقارير الصحية السنوية لوزارة الصحة. 
يعاني القطاع الصحي كغيره من القطاعات الخدمية للأهمال الحكومي بسبب الأزمات المتعاقبة وتدهور البنية التحتية لمختلف القطاعات الاقتصادية كل هذه العوامل ساعدت على بروز ضعف الفئ الخدمات الصحية المقدمة للمو اطنين وتؤشر

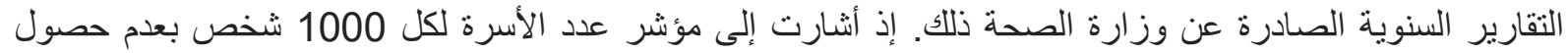

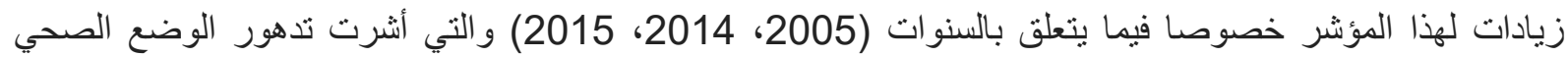
بسبب الأعمال الإرهابية التي طالت عدد من المحافظات. ج - مؤشر عدد الأطباء لكل 1000 شخص:

يعكس مؤشر عدد الأطباء مستوى الصحة العامة والخدمات المقدمة للمرضى كما بين المؤشر مدى التقدم الذي وصلتإليه

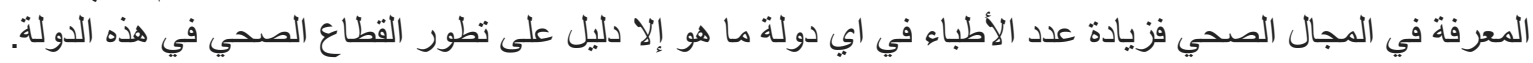

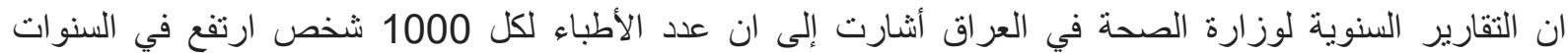

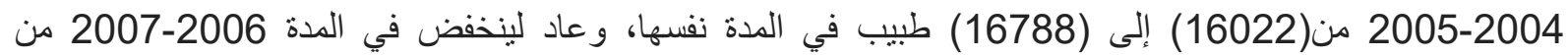

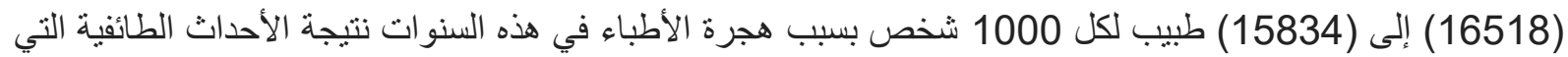

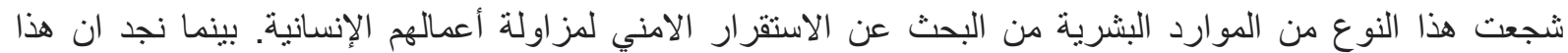

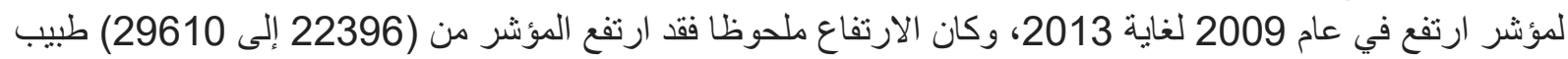

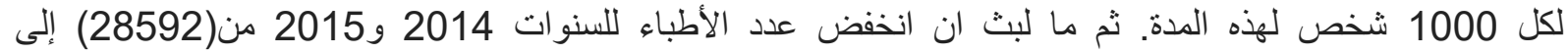

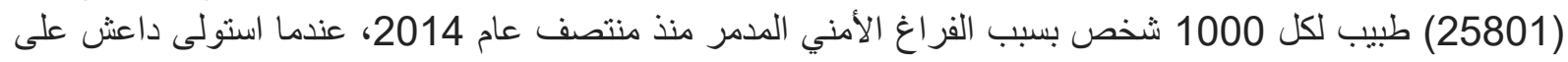

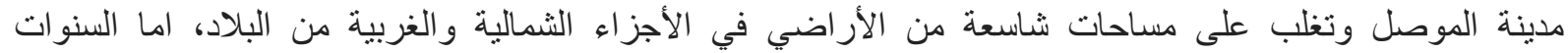

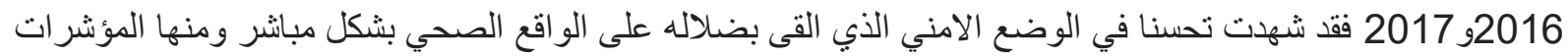

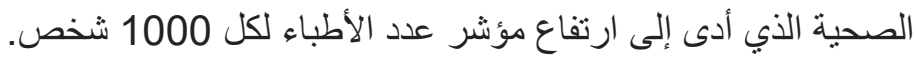

جدول (2) مؤشر الإنفاق على الصحة ونصيب الفرد من الإنفاق للفترة (2004- 2017)

\begin{tabular}{|c|c|c|c|c|c|c|c|}
\hline نسبة الإنفاق & 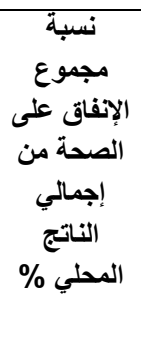 & الإلمرالي من & من منبب الفرد & 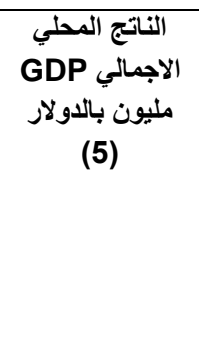 & 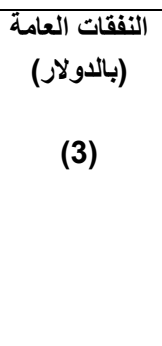 & الإنفاق على الصحة & السنة \\
\hline 0.7256 & 0.1855 & 0.036 & 1349.0 & 53235358.7 & 22104.26 & 1، 788، 257، 4 & 2004 \\
\hline 43.8831 & 0.8762 & 0.230 & 1785.3 & 73533598.6 & 17954.51 & 1.469 .086 .2 & 2005 \\
\hline 5.1839 & 0.8126 & 0.027 & 2231.9 & 95587954.8 & 22827.46 & 1.637 .696 .9 & 2006 \\
\hline 4.2395 & 0.7939 & 0.030 & 2966.0 & 111455813.4 & 31100.58 & 1.789 .216 .0 & 2007 \\
\hline 3.9260 & 0.6535 & 0.034 & 4258.1 & 157026061.6 & 49793.27 & 2.708 .934 .1 & 2008 \\
\hline 4.0057 & 0.8437 & 0.035 & 3526.4 & 130643200.4 & 44929.08 & 2.666 .786 .2 & 2009 \\
\hline 4.4575 & 0.8433 & 0.042 & 4263.4 & 162064565.5 & 55001.70 & 3.823 .056 .5 & 2010 \\
\hline 4.3732 & 0.8603 & 0.056 & 5571.6 & 217327107.4 & 67314.24 & 4.591 .914 .2 & 2011 \\
\hline
\end{tabular}




\begin{tabular}{|c|c|c|c|c|c|c|c|}
\hline 10.0210 & 1.6618 & 0.124 & 6373.9 & 254225490.7 & 90171.16 & 4.047 .971 .3 & $\mathbf{2 0 1 2}$ \\
\hline 9.4510 & 1.6497 & 0.129 & 6685.6 & 273587529.2 & 91657.83 & 4.930 .391 .2 & $\mathbf{2 0 1 3}$ \\
\hline 10.0467 & 1.8087 & 0.138 & 6560.0 & 266332655.1 & 70333.52 & 4.283 .254 .1 & $\mathbf{2 0 1 4}$ \\
\hline 13.0449 & 2.4350 & 0.135 & 4737.6 & 194680971.8 & 59157.58 & 3.772 .844 .9 & $\mathbf{2 0 1 5}$ \\
\hline 14.0366 & 2.5812 & 0.141 & 4606.2 & 196924141.7 & 56359.19 & 4.009 .530 .7 & $\mathbf{2 0 1 6}$ \\
\hline 14.5623 & 2.3744 & 0.142 & 5049.5 & 221665709.5 & 63866.42 & 3.298 .298 .9 & $\mathbf{2 0 1 7}$ \\
& & & & & & & \\
\hline
\end{tabular}

المصدر: وزارة التخطبط، الجهاز المركزي للاحصاء، الحسابات القومية.

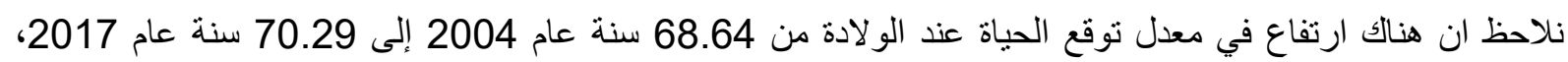

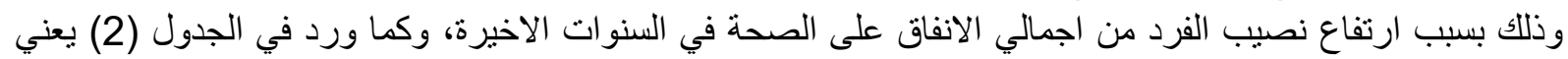

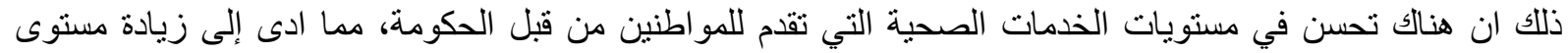

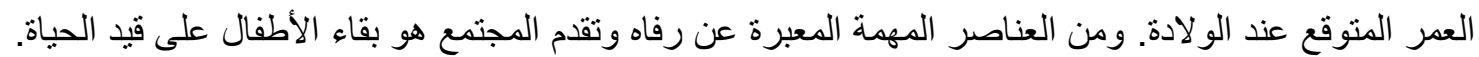

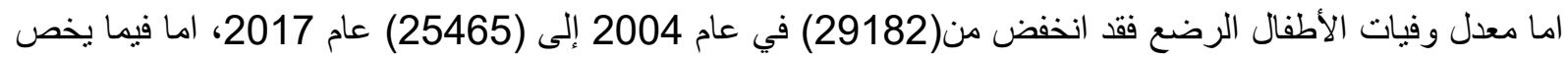

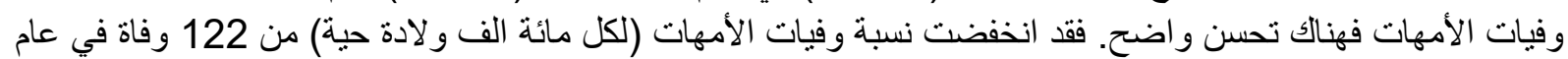

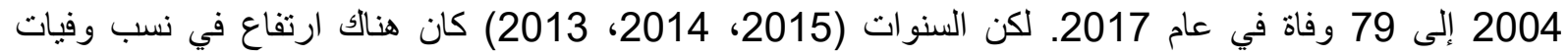

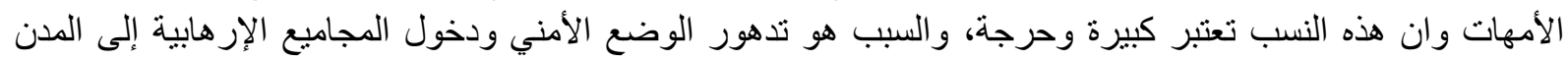
و التي أدت إلى نزوح عدد كبير من السكان.

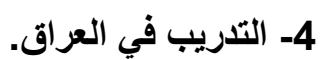

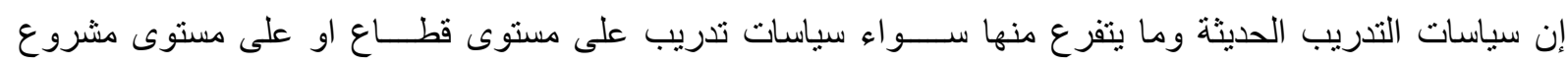

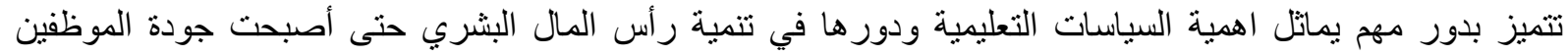

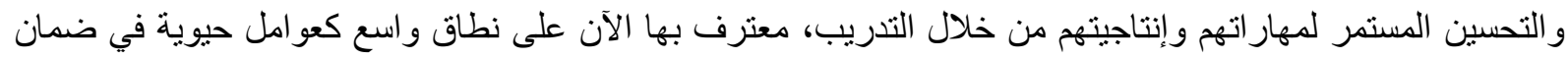

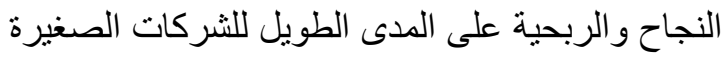

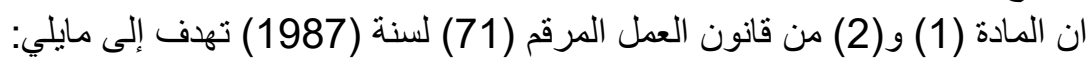

ـالمادة(1) تهدف إلى التدريب المهني كذلك تستهدف شريحة العاملين المبتدئين لغرض إعلى إعدادهم وتأهيلهم وتمدهم بالخبرات الفنية لكافة انواع العمل بالإضافة إلى تطوير المستويات الفنية للعاملين المهرة ورفع مسنوى كفاءتهم الإنتاجية -المادة (2) وتسري تعليمات هذه المادة على المهن التي يتدرب عليها العمال في القطاع (الخاص، و المختلط، و التعاوني)

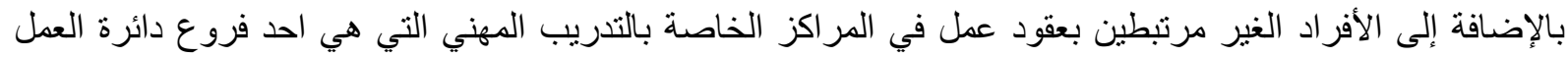

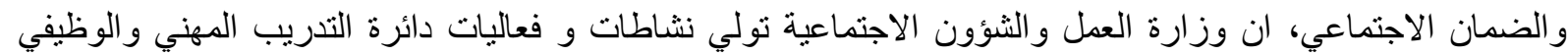

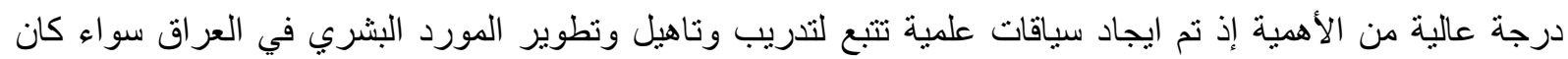

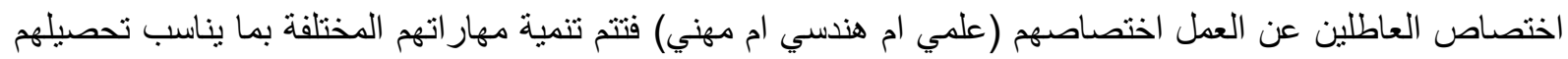

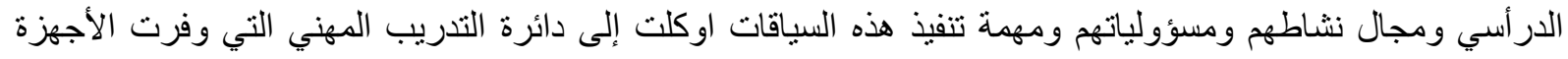

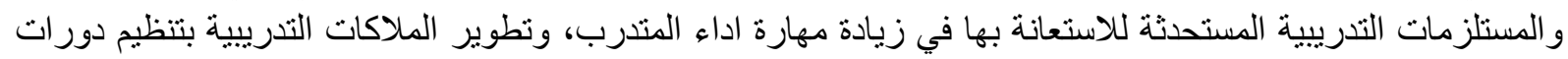

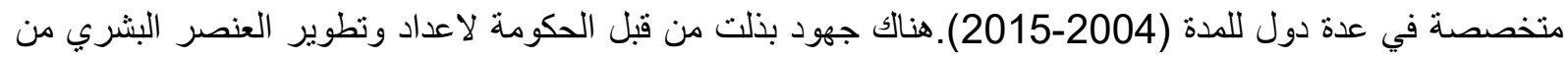

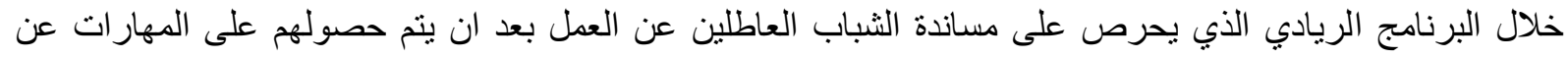
طريق مشاركتهم في الدورات الندريبية المهنية ومن هذه البر امجن: - برنامج (كاب) 
ثانيا- تحليل مؤشرات النمو الاقتصادي في العراق للمدة (2004_2017).

يُعد النمو الاقتصادي من أهم المؤشرات التي تعبر عن مستوى التقام للمجتمعات.لقد درج الاقتصاديين على استعمال جملة

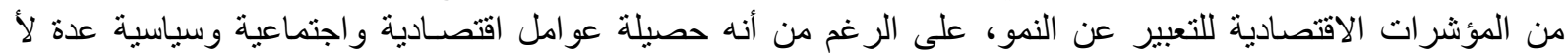

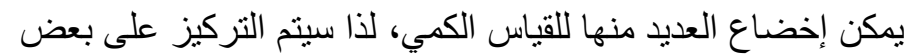

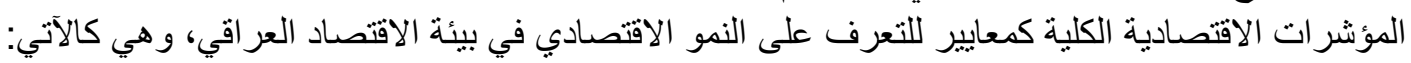

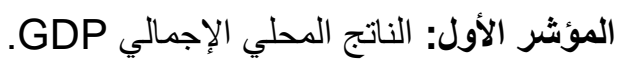

المؤشر الثاني: منوسط نصيب الفرد من الناتج المحلي الإجمالي

ثالثا. تحليل مؤشرات الناتج المحلي الإجمالي في العراق للمدة2004_2017).

يشير الناتج المحلي الإجمالي GDP إلى "قيمة السلع والخدمات النهائية (التامة الصنع) المنتجة داخل الرقعة الجغر افية

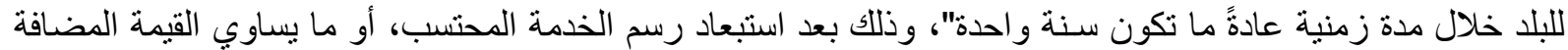

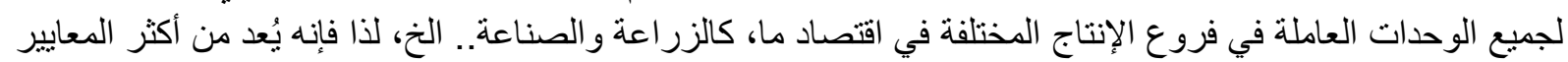

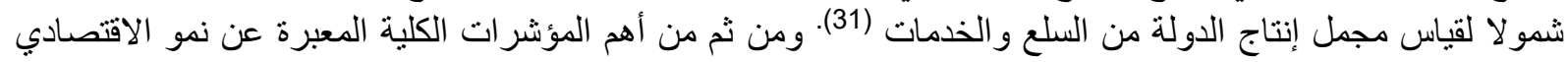

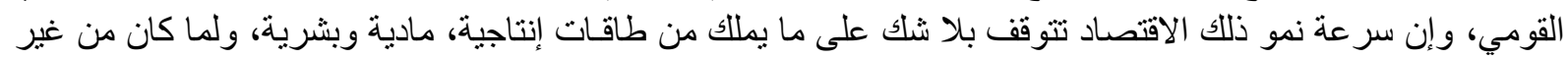

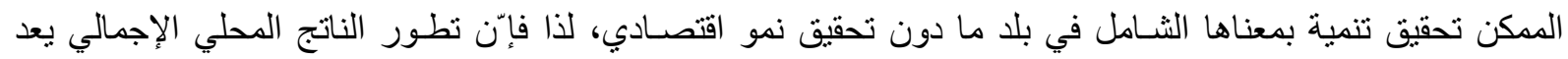

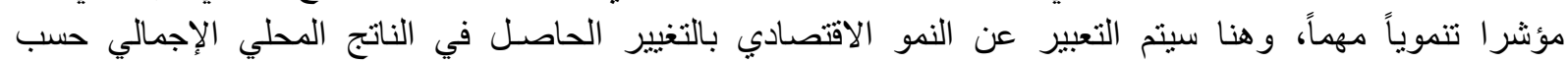

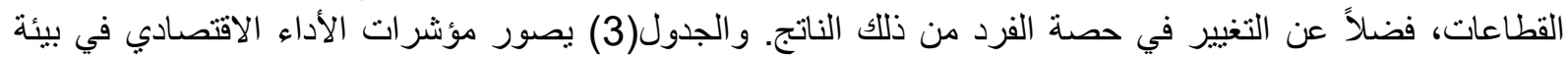

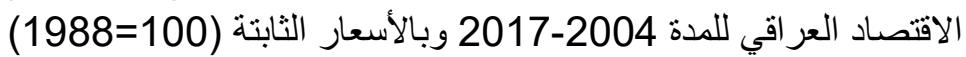

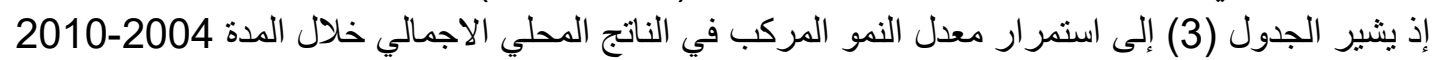

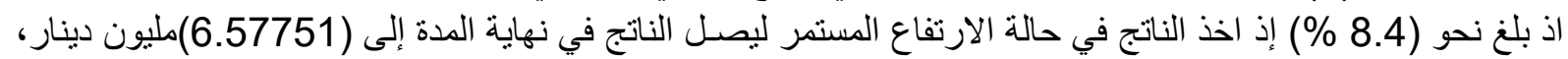

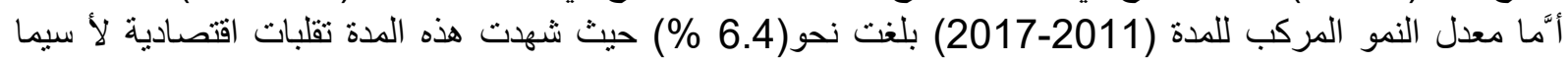

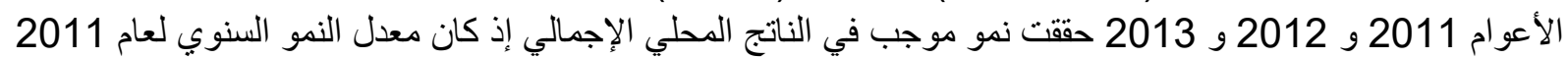

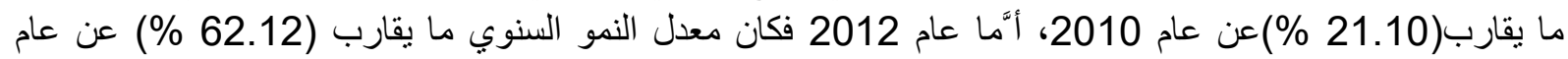

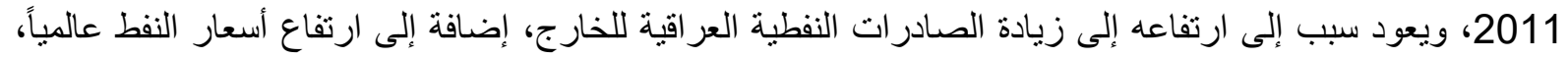

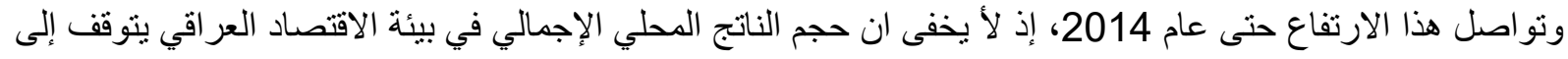

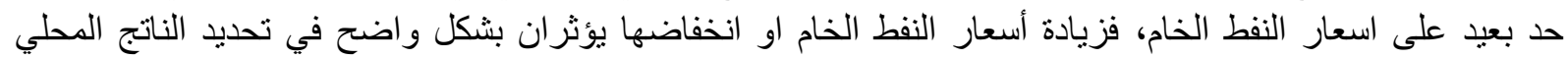

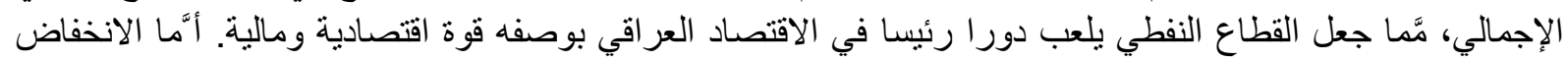

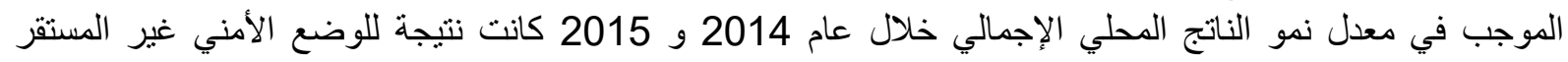

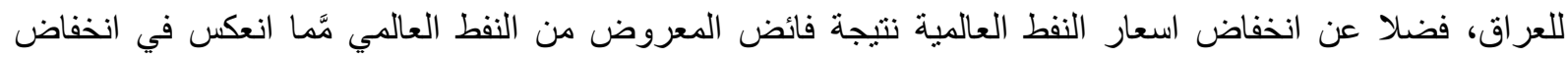

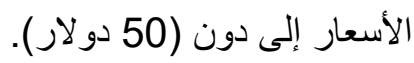

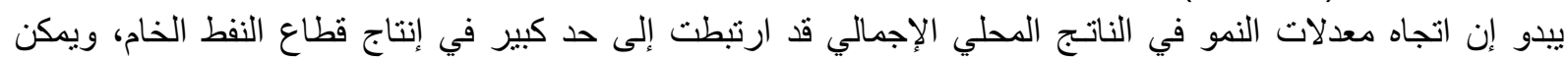

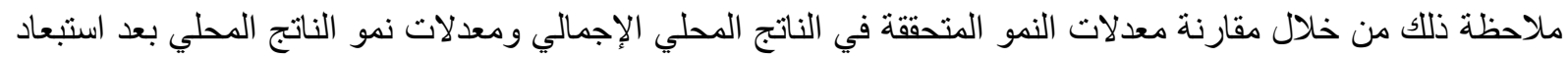

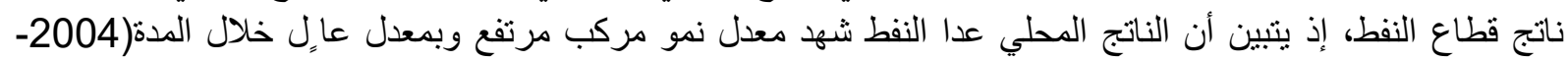

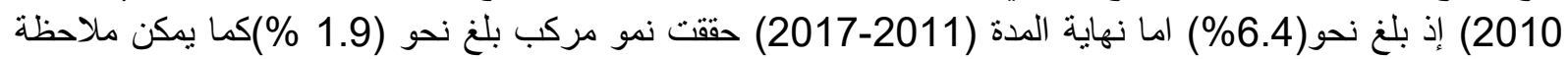
عمق الفجوة الكبيرة بين الناتج المحلي الإجمالي والناتج المحلي عدا النية النفط، وهذا يعبر عن اختلال كبير في هيكل للتقلبات التي تحدث في أسواق النفط العالمية.

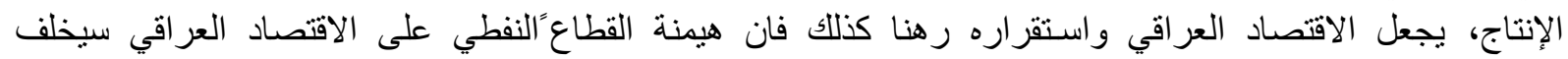

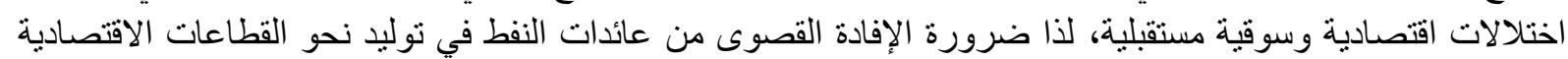
الأخرى. 
جدول (3) مؤشر ات الناتج المحلي الإجمالي في بيئة الاقتصاد العر اقي للددة 2004-2017 مليون دينار (1988 = 100)

\begin{tabular}{|c|c|c|c|c|}
\hline معدل النمو الناتج المحلي & $\begin{array}{l}\text { لناتج المحلي الاجمالي }=2=1 \\
3=2+1\end{array}$ & النفط الخام & الناتج المحلي الاجمالي & السنة \\
\hline 54.16 & 41607.8 & 42.19 & 21818.4 & 2004 \\
\hline 4.40 & 43438.8 & 7.43- & 25119.2 & 2005 \\
\hline 10.16 & 47851.4 & 5.5 & 28523.9 & 2006 \\
\hline 1.38 & 48510.6 & 7.51 & 277321.1 & 2007 \\
\hline 6.61 & 51716.6 & 12.48 & 28344.9 & 2008 \\
\hline 5.81 & 54721.2 & 2.17 & 30843.5 & 2009 \\
\hline 5.54 & 57751.6 & 0.93 & 33652.0 & 2010 \\
\hline 10.21 & 63650.4 & 12.55 & 36527.0 & 2011 \\
\hline 12.62 & 71680.8 & 12.9 & 41058.5 & 2012 \\
\hline 7.31 & 76922.0 & 3.2 & 45319.8 & 2013 \\
\hline 1.13 & 77789.7 & 4.35 & 44812.8 & 2014 \\
\hline 2.61 & 79817.5 & 15.93 & 41586 & 2015 \\
\hline 13.79 & 90822.2 & 24.41 & 43257.3 & 2016 \\
\hline 3.77- & 87399.9 & 4.11- & 41789.7 & 2017 \\
\hline & $\begin{array}{l}4.8 \\
4.6\end{array}$ & $\begin{array}{c}2.86 \\
7.7\end{array}$ & $\begin{array}{l}6.4 \\
1.9\end{array}$ & معدل النمو المركب \\
\hline
\end{tabular}

المصدر: وزارة التخطيط، الجهاز المركزي للإحصاء، النشرة الاحصائية السنوية

رابعا- تحليل مؤشر نصيب الفرد من الناتج المحلي الإجمالي في العراق للمدة (2004_2017).

على الرغم من أن تطور منوسط نصيب الفرد من الناتج المحلي الإجمالي (GDP) قد لأ يعبر عن الهدف الحقيقي للتنمية

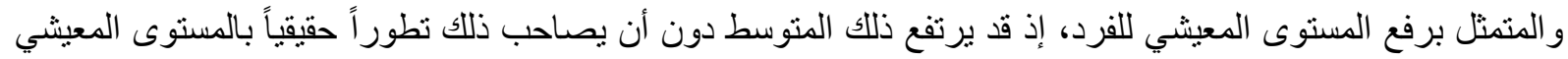

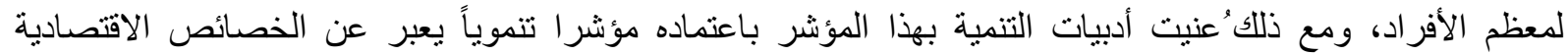

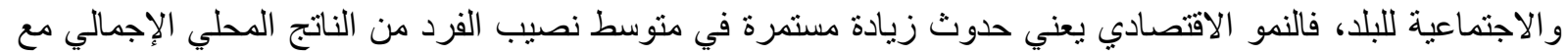

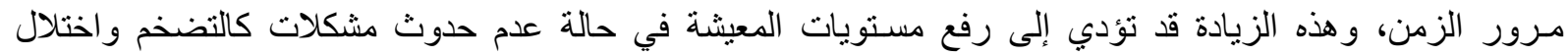
موازين المدفوعات و عدالة التوزيع.

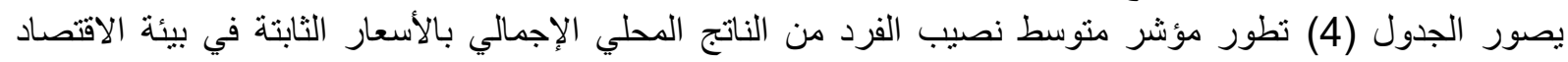

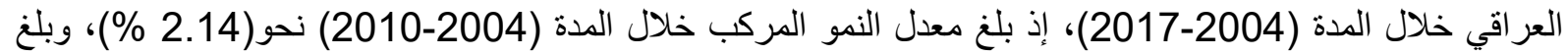

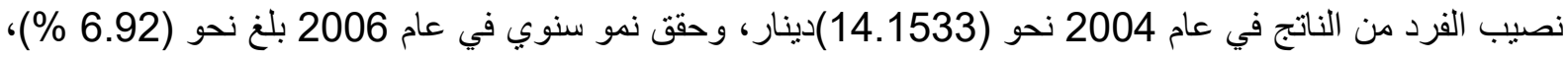

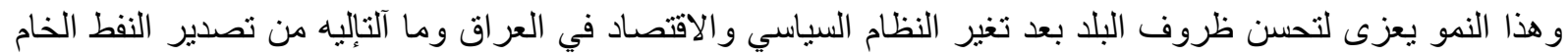

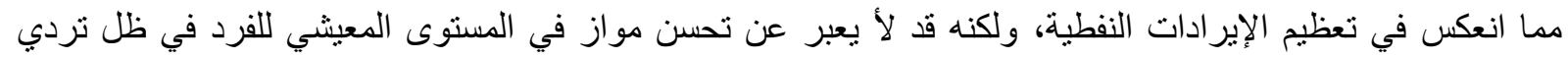
البنى التحتية و الخدمات الاجتماعية.

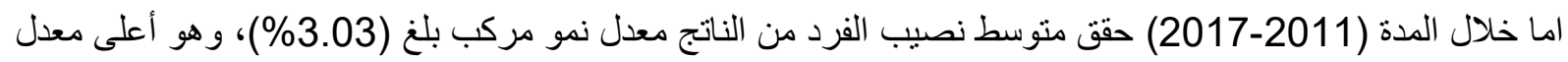

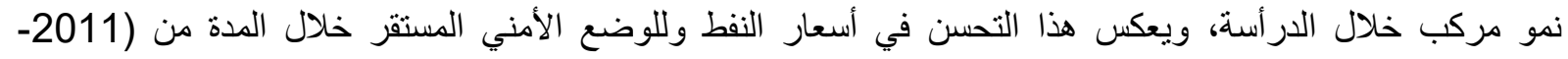

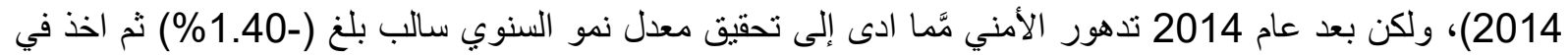

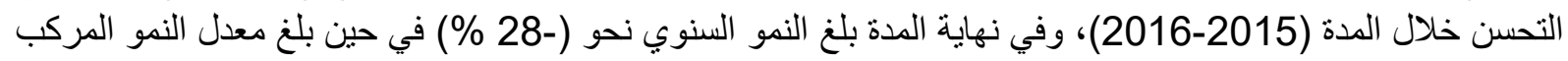

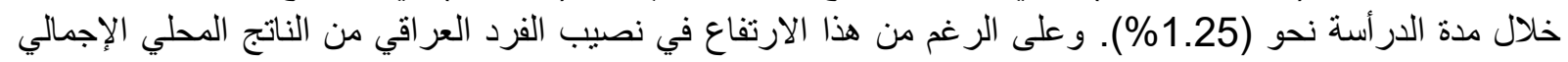

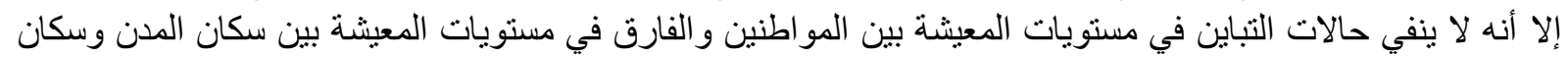

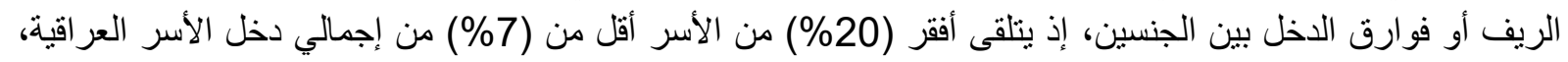

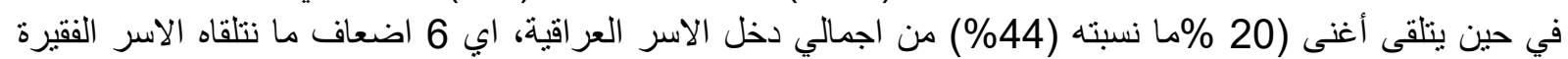
(34) ما يدل على سوء الدخل بين فئات المجتمع. 
THE IRAQI ECONOMY FOR THE PERIOD (2004-2017)

جدول (4) منوسط نصيب الفرد من الناتج المحلي الاجمالي في بيئة الاقتصاد العر اقي (2004-2017)

\begin{tabular}{|c|c|c|c|c|}
\hline $\begin{array}{c}\text { معدل النمو متوسط \% } \\
\text { \% الاخل }\end{array}$ & متوسط نصيب الفرد & عدد السكان & الاتجمالي المحلي & السنوات \\
\hline 49.62 & 1533.14 & 27.139 & 41607.8 & 2004 \\
\hline 1.32 & 1553.44 & 27.963 & 43438.8 & 2005 \\
\hline 6.92 & 1660.93 & 28.810 & 47851.4 & 2006 \\
\hline $1.60-$ & 1634.34 & 29.682 & 48510.6 & 2007 \\
\hline 0.79 & 1621.46 & 31.892 & 51716.6 & 2008 \\
\hline 6.58 & 1728.18 & 31.664 & 54721.2 & 2009 \\
\hline 2.85 & 1777.52 & 32.490 & 57751.6 & 2010 \\
\hline 7.41 & 1909.24 & 33.338 & 63650.4 & 2011 \\
\hline 9.75 & 2095.44 & 34.208 & 71680.8 & 2012 \\
\hline 4.60 & 2191.76 & 35.096 & 76922.0 & 2013 \\
\hline $1.40-$ & 2160.52 & 36.005 & 77789.7 & 2014 \\
\hline 4.90 & 2266.71 & 35.213 & 79817.5 & 2015 \\
\hline 10.78 & 2511.05 & 36.169 & 90822.2 & 2016 \\
\hline $6.28-$ & 2353.26 & 37.140 & 87399.9 & 2017 \\
\hline & $\begin{array}{l}2.14 \\
3.03\end{array}$ & $\begin{array}{l}2.61 \\
1.56\end{array}$ & $\begin{array}{l}4.80 \\
4.60\end{array}$ & معدل النمو المركب 2010 2011 2017-2011 \\
\hline
\end{tabular}

المصدر: وزارة التخطيط، الجهاز المركزي للإحصاء، النشرة الاحصائية السنوية

الاستنتاجات والتوصيات

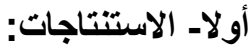

1- يعاني ر أس المال البشري من الإهمال في مجالات التدريب والتأهيل ومواكبة التطورات العلمية و التكنولوجية العالمية.

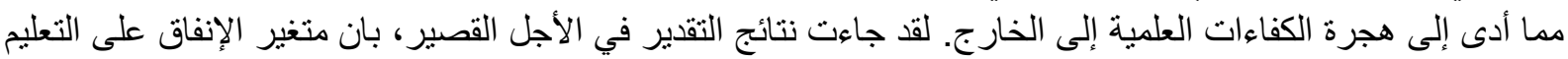

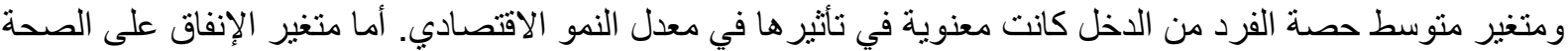
فلم يكن معنويا في تأثيره في معدل النمو الاقتصادي. 2- أن و اقع التعليم في العراق لافيره فيلبي منطلبات التحول نحو اقتصاد المعرفة إذ لا يزال يعاني هذا القطاع من الإهمال الحكومي المتمثل في نقص البنى التحنية. 3- تذبذب معدل نمو الناتج المحلي الإجمالي ومنوسط نصيب الفئل الفرد في بيئة الاقتصاد العراقي خلال المادة(20042017) و هذا ينتج عن التقلبات الاقتصادية والسياسية التي مرت بالاقتصاد العر اقي والتداعيات أحداث عام 2003.

ثثاتيا- التوصيات: - ات

1.ضرورة وجود تناغم بين سياسات التعليم وتهيئة الكوادر التقنية والمهنية مع متطلبات النمو الاقتصادي لغرض رفع كفاءة الأيدي العاملة وقدرته الإنتاجية.

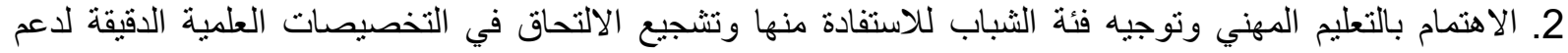

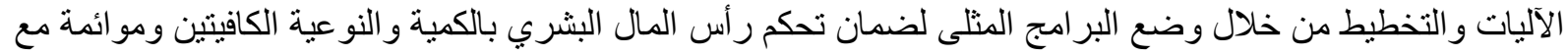
منطلبات الاقتصاد الوطني. 
3. بالنظر لان التعليم هو المكون الأكبر، لرأس المال البشري فلابد ان تكون القيمة المضافة له، ترتبط بمستوى مساهمته

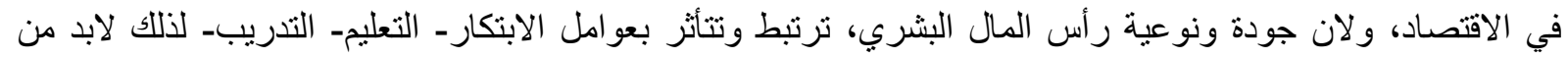

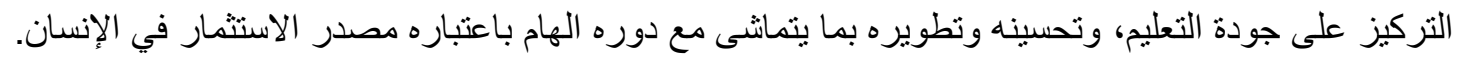

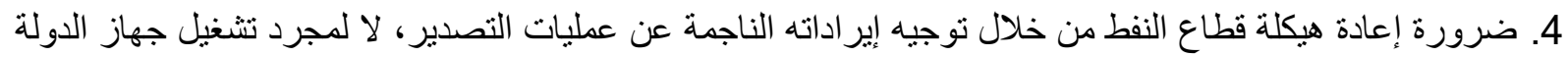

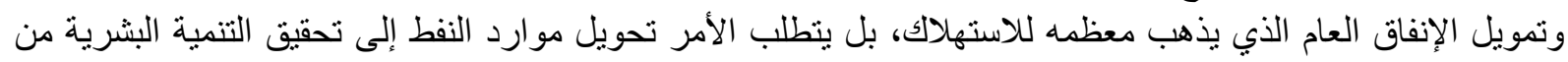
خلال الاستثمار في بناء رأس المال البشري وتحديث البنى الارتكازية وتتويع القاعدة الإنتاجية.

المصادر

العلي، عبد الستار، واخرون، الدذخل إلى المعرفة، دار المسيرة للنشر و التوزيع و الطباعة، ط1، عمان الاردن

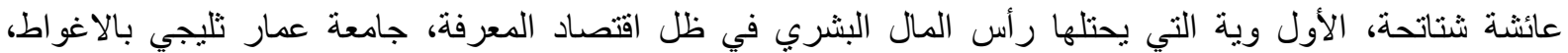

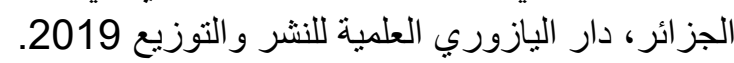

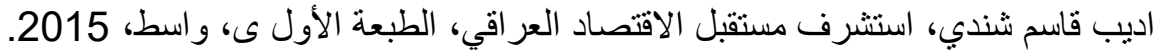

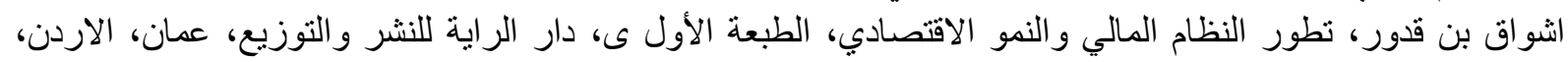
.2013

رسائل و إطاريح:

محد منبر عودة شبير، دور أنظمة ذكاء الاعمال في تتمية رأس المال البشري في القطاع المصرفي الفلسطيني. رسالة

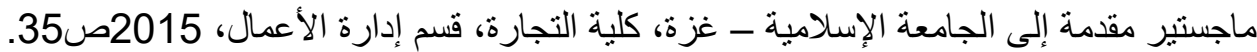

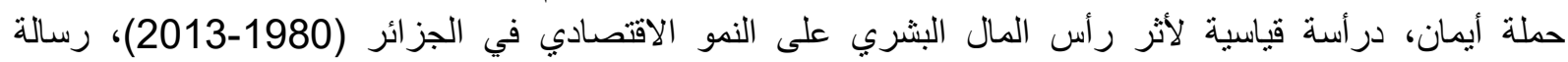

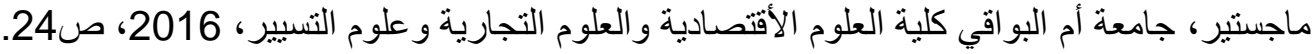

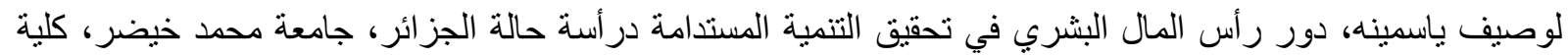

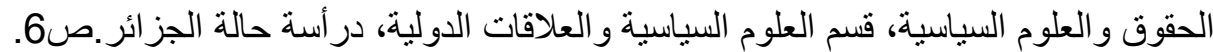

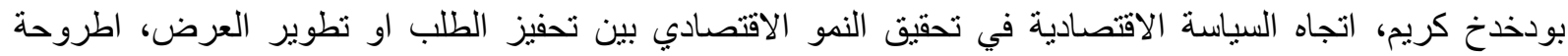

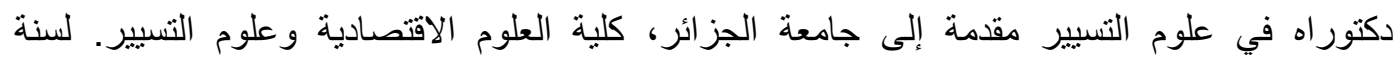

\section{5}

نادية ابراهيمي، دور الجامعة في تتمية رأس المال البشري لتحقيق التتمية المستدامة، جامعة المسيلة، رسالة ماجستير

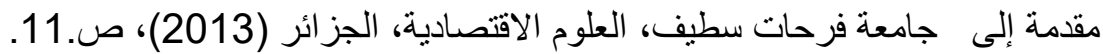

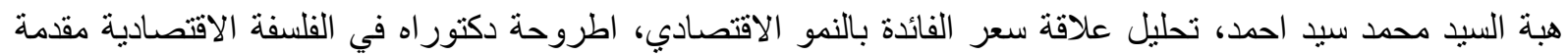

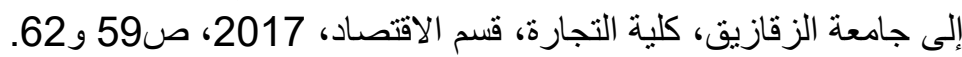

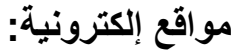

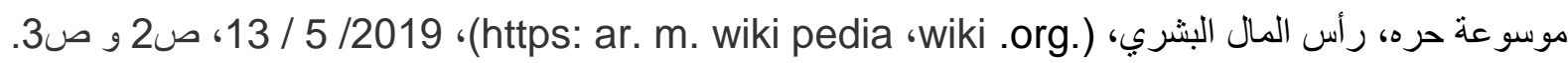
Reviewed by WILL KENTON Updated May 28, 2019.

https://www.investopedia.com/terms.

./h/Humancapital.asp

مجموعة البنك الدولي، نبذة عن مشروع رأس المال البشري، التقرير المرحلي السنوي الأول ، 2018 الموقع

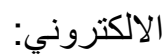

،2018.https://www.albankaldawli.org/ar/publication/human-capital/brief/about-hcp

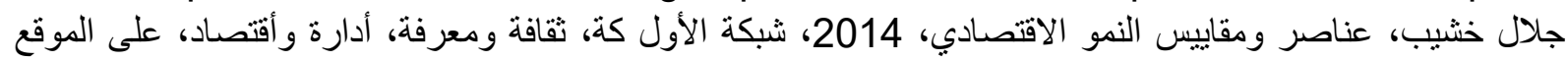
https://www.alukah.net/culture/0/79206/المتاح: 
برنامج الأمم المتحدة الانمائي، تقرير مؤشر المعرفة العربي، 2016، دبي، على الموقع المتاح: https://www.knowledge4all.com/admin/uploads/files/AKI2016/ArabKnowle dgelndex2016_Arabic.pdf

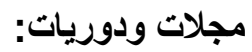

سندس شعيب وشذى سالم ولي - رأس المال البشري ودوره في تعزيز مؤشرات اقتصاد المعرفة وتلبية احتياجات سوق

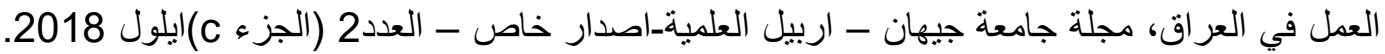

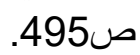

الدباش، عبد الله حمد، وآخرون، قياس مؤشرات رأس المال البشري في العراق للمدة 2010- 2012، مجلة جامعة

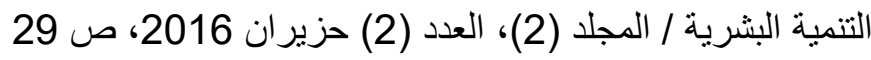

جعفر علوش، حساب معدل نمو الإنتاجية الكلية لعو امل الإنتاج في الاقتصاد العزب العز اقي باستخدام نموذج سولو المطور للمدة

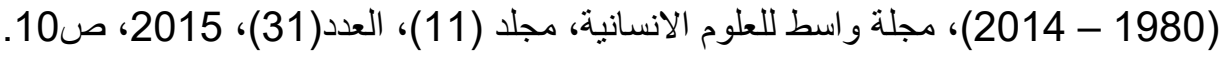

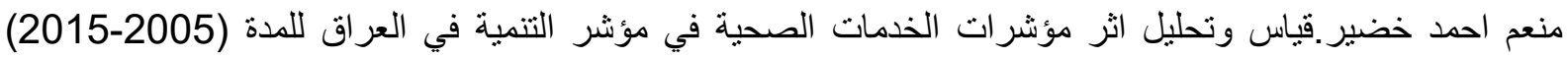
مجلة تكريت، كلية الادارة ولاقتصاد، ، مجلة تكريت للعلوم الادارية والاقتصادية، المجلد (2) العدد 38،

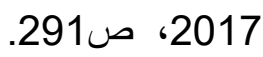
مذكرات وقوانين وتقارير:

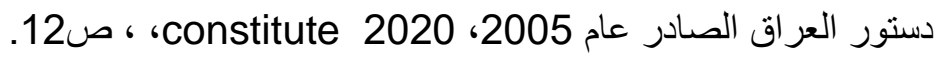
${ }^{1}$ https://www.inc.com/encyclopedia/training-and-development.html

قانون العمل رقم (71) لسنة 1987.

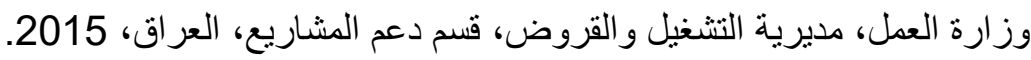
وزارة التخطيطو التعاون الانمائي، التقرير الوطني لحال التنمية البشرية 2008، بغداد، 2009.

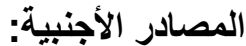

Futoshi Yamauchi ،HUMAN CAPITAL FORMATION ،history، Expectations and challenges، in South Africa ‘2010.

Solow ‘R.M.(1956."A Contribution of the Theory of Economic Growth". Quarterly Journal of Economics. Vol 70 No 1. PP ،65-94 